SVERIGES RIKSBANK

WORKING PAPER SERIES

163

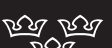

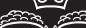

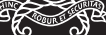

Exchange Rate Puzzles:

A Tale of Switching Attractors

Paul De Grauwe and Marianna Grimaldi

MAY 2004 
WORKING PAPERS ARE OBTAINABLE FROM

Sveriges Riksbank •Information Riksbank • SE-103 37 Stockholm Fax international: +4687870526

Telephone international: +4687870100

E-mail: info@riksbank.se

The Working Paper series presents reports on matters in the sphere of activities of the Riksbank that are considered to be of interest to a wider public.

The papers are to be regarded as reports on ongoing studies and the authors will be pleased to receive comments.

The views expressed in Working Papers are solely the responsibility of the authors and should not to be interpreted as reflecting the views of the Executive Board of Sveriges Riksbank. 


\title{
Exchange rate puzzles: A tale of switching attractors
}

\author{
Paul De Grauwe \\ Marianna Grimaldi* \\ University of Leuven \\ Sveriges Riksbank \\ Sveriges Riksbank Working Paper Series \\ No. 163 \\ May 2004
}

\begin{abstract}
The rational expectations efficient market model of the exchange rate has failed empirically. In this paper we develop a model of the exchange rate in which agents use simple forecasting rules. Based on an ex post evaluation of the relative profitability of these rules they decide whether to switch or not. In addition, transactions costs in the goods market are introduced. We show that this simple model creates great complexity in the market which is characterised by the fact that the exchange rate is disconnected from its fundamental most of the time. Finally we show that this model mimicks most of the empirical puzzles uncovered in the literature.
\end{abstract}

JEL classification: F31, F41

Keywords: Exchange rate, heterogeneous agents, technical trading, transaction costs.

\footnotetext{
${ }^{*}$ We are very grateful for useful comments to Volker Bohm, Yin-Wong Cheung, Hans Dewachter, Roberto Dieci, Marc Flandreau, Philip Lane, Thomas Lux, Richard Lyons, Ronald McDonald, Michael Moore, Assaf Razin, Piet Sercu, Peter Sinclair, Peter Westaway. We also gratefully acknowledge the comments and suggestions of two anonymous referees. The views expressed in this paper are solely the responsibility of the authors and should not be interpreted as reflecting the views of the Executive Board of Sveriges Riksbank.

${ }^{\dagger}$ Corresponding address: Paul De Grauwe, paul.degrauwe@econ.kuleuven.ac.be.
} 


\section{Introduction}

The rational expectations efficient market model developed during the 1970s has dominated our thinking about exchange rates. This model led to the following propositions. First, exchange rate changes can only occur because of unexpected movements (news) in the underlying fundamental economic variables (inflation, output growth, interest rates, etc.). Second, the link between exchange rates and fundamentals is a stable one. Well-known examples of the rational expectation efficient market model is the monetary model, the Dornbusch model (Dornbusch(1976)) and the portfolio balance model. Although these models continue to be popular and maintain a prominent place in textbooks, they have failed empirically. The most notorious empirical rejection was made by Meese and Rogoff at the beginning of the 1980s (Meese and Rogoff(1983)). This led to a large empirical literature that uncovered a number of empirical puzzles concerning the behaviour of the exchange rate, which could not be explained by the 'news' models.

The first and foremost empirical puzzle has been called the "disconnect" puzzle, i.e. the exchange rate appears to be disconnected from its underlying fundamentals most of the time. Goodhart (1989), Goodhart and Figlioli (1991) and more recently Faust et al. (2003) found that most of the changes in the exchange rates occur when there is no observable news in the fundamental economic variables.

Other empirical anomalies have been uncovered over the years. One is the puzzle of "excess volatility" of the exchange rate, i.e. the volatility of the exchange rate by far exceeds the volatility of the underlying economic variables (Baxter and Stockman (1989) and Flood and Rose (1995)).

Another puzzle is that the distribution of the exchange rate returns is not normal. Most of the empirical findings document that the exchange rate returns have fat tails (see de Vries(2001), Lux T. (1997, 1998), Lux and Marchesi (1999, 2000). This evidence is difficult to rationalise in existing exchange rate models, since there is little evidence of fat tails in the fundamental variables that drive the exchange rate in these models.

The empirical failure of the exchange rate models of the 1970s has led to new attempts to model the exchange rate. These attempts have led to three different modelling approaches. The first one uses the Obstfeld-Rogoff framework of dynamic utility optimisation of a representative agent. This approach although promising is still waiting for empirical confirmation (Obstfeld and Rogoff (1996)).

A second approach starts from the analysis of the microstructure of the foreign exchange market (Evans and Lyons (1999), Lyons (2001)). This approach has led to new insights into the way information is aggregated and is important for the understanding of the short-term behaviour of the exchange rate.

Finally, a third approach recognises that heterogeneous agents have different beliefs about the behaviour of the exchange rate. These different beliefs introduce non-linear features in the dynamics of the exchange rate. This approach was developed mainly in the context of stock prices (Kirman (1993), Brock and 
Hommes(1997), (1998), Lux (1998), Le Baron, et al.(1999), Gaunersdorfer and Hommes(2003)). Our paper is based on this third approach.

Recently, heterogeneity of agents has also been introduced in rational expectations models. (See e.g. Bacchetta and van Wincoop(2003)). The implication of rational expectations in models with heterogeneous agents is that it creates "infinite regress", i.e. the exchange rate depends on the expectations of other agents' expectations, which depends on the expectations of the expectations of other agents' expectations, and so on, ad infinitum. This leads to intractable mathematical problems except under very restrictive simplifying assumptions. Although this approach is intellectually satisfying, it is unclear that it is a good representation of what agents do in the exchange market. It requires these agents to solve a mathematical problem to which mathematicians have as yet been unable to give a general solution. This seems to us as imposing too large an informational burden on individual agents.

Our approach contrasts with this rational expectations approach in that agents use simple rules, the "fitness" of which is then controlled ex post by checking their profitability, and by switching to the more profitable rules. We will use the switching mechanism introduced by Brock and Hommes in their seminal article to formalize this idea (see Brock and Hommes(1997)). In addition, we make use of the recent empirical evidence, which has stressed the importance of transactions costs in the goods market for our understanding of the dynamics of exchange rate adjustments (Michael, Nobay, Peel (1997), O' Connell (1998), Obstfeld and Rogoff (2000), Engel(2000) and Kilian and Taylor (2001)). We show that our model is capable of replicating the empirical puzzles and anomalies uncovered in the last decade by the empirical exchange rate literature.

The paper is organised as follows. In section 2 we present the theoretical model. In sections 3,4 , and 5 we analyse its features, while in sections 6,7 and 8 we analyse its empirical predictions. We conclude in section 9 .

\section{The model}

In this section we develop a simple non-linear model of the exchange rate. The model consists of three building blocks. First, agents decide the optimal portfolio using a mean-variance utility framework. Second, they make forecasts about the future exchange rate based on simple rules. Third, they evaluate these rules ex-post by comparing their risk-adjusted profitability (Brock-Hommes(1997)).

\subsection{The optimal portfolio}

We assume agents of different types $i$ depending on their beliefs about the future exchange rate. Each agent can invest in two assets, a domestic and a foreign one. The agents' utility function can be represented by the following equation:

$$
U\left(W_{t+1}^{i}\right)=E_{t}^{i}\left(W_{t+1}^{i}\right)-\frac{1}{2} \mu V_{t}^{i}\left(W_{t+1}^{i}\right)
$$


where $W_{t+1}^{i}$ is the wealth of agent of type $i$ at time $t+1, E_{t}^{i}$ is the expectation operator of agent of type $i, \mu$ is the coefficient of risk aversion and $V_{t}^{i}\left(W_{t+1}^{i}\right)$ represents the conditional variance of wealth of agent $i$. The wealth is specified as follows:

$$
W_{t+1}^{i}=\left(1+r^{*}\right) s_{t+1} d_{i, t}+(1+r)\left(W_{t}^{i}-s_{t} d_{i, t}\right)
$$

where $r$ and $r^{*}$ are respectively the domestic and the foreign interest rates, $s_{t+1}$ is the exchange rate at time $t+1, d_{i, t}$ represents the holdings of the foreign assets by agent of type $i$ at time t. Thus, the first term on the right-hand side of 2 represents the value of the foreign portfolio in domestic currency at time $t+1$ while the second term represents the value of the domestic portfolio at time $\mathrm{t}+1$.

Substituting equation 2 in 1 and maximising the utility with respect to $d_{i, t}$ allows us to derive the optimal holding of foreign assets by agents of type $i$ :

$$
d_{i, t}=\frac{\left(1+r^{*}\right) E_{t}^{i}\left(s_{t+1}\right)-(1+r) s_{t}}{\mu \sigma_{i, t}^{2}}
$$

where $\sigma_{i, t}^{2}=\left(1+r^{*}\right)^{2} V_{t}^{i}\left(s_{t+1}\right)$. Thus, the optimal holdings of the foreign asset depend on both the heterogenous beliefs about the future level of the exchange rate and its variance. Note that our model is more general than the influential model of Brock and Hommes $(1997,1998)$ who studied the case of constant and equal variances for all types of agents ${ }^{1}$.

The market demand for foreign assets at time $t$ is the sum of the individual demands, i.e.:

$$
\sum_{i=1}^{N} n_{i, t} d_{i, t}=D_{t}
$$

where $n_{i, t}$ is the number of agents of type $i$.

Market equilibrium implies that the market demand is equal to the market supply $X_{t}$ which we assume to be exogenous ${ }^{2}$. Thus,

$$
X_{t}=D_{t}
$$

Substituting the optimal holdings into the market demand and then into the market equilibrium equation and solving for the exchange rate $s_{t}$ yields the market clearing exchange rate:

$$
s_{t}=\left(\frac{1+r^{*}}{1+r}\right) \frac{1}{\sum_{i=1}^{N} \frac{w_{i, t}}{\sigma_{i, t}^{2}}}\left[\sum_{i=1}^{N} w_{i, t} \frac{E_{t}^{i}\left(s_{t+1}\right)}{\sigma_{i, t}^{2}}-\Omega_{t} X_{t}\right]
$$

\footnotetext{
${ }^{1}$ Gaunersdorfer(2000) extended the Brock-Hommes model by allowing time varying but homogenous beliefs concerning the variances. Chiarella and $\mathrm{He}(2002)$ extended the model to allow for time varying and heterogenous beliefs about varainces.

${ }^{2}$ The market supply is determined by the net current account and by the sales or purchases of foreign exchange of the central bank. We assume both to be exogenous. In an extension of this paper we intend to endogenise the market supply.
} 
where $w_{i, t}=\frac{n_{i, t}}{\sum_{i=1}^{N} n_{i, t}}$ is the weight of agent $i$, and $\Omega_{t}=\frac{\mu}{\left(1+r^{*}\right) \sum_{i=1}^{N} n_{i, t}}$. In the following we will set $r=r^{*}$.

\subsection{The forecasting rules}

We assume that there are two types of agents: chartists (technical traders) and fundamentalists. Here we specify how fundamentalists and chartists form their expectations of the future exchange rate. Then we will specify how they take into account the risk as measured by the variances.

The fundamentalists base their forecast on a comparison between the market and the fundamental exchange rate, i.e. they forecast the market rate to return to the fundamental rate in the future. In this sense they use a negative feedback rule that introduces a mean reverting dynamics in the exchange rate. The speed with which the market exchange rate returns to the fundamental is assumed to be determined by the speed of adjustment in the goods market. Thus, the forecasting rule for the fundamentalists is:

$$
E_{t}^{f}\left(\Delta s_{t+1}\right)=-\psi\left(s_{t-1}-s_{t-1}^{*}\right)
$$

where $s_{t-1}^{*}$ is the fundamental exchange rate at time $t-1$, which is assumed to follow a random walk and $0<\psi<1$. Note the timing of the information set. In the Walrasian market equilibrium framework used here, the market clearing exchange rate depends on forecasts of $s_{t+1}$. When forming this forecast agents have not yet observed $s_{t}$. As a result, they use the most recent observed exchange rate, $s_{t-1}$.

In addition, the fundamentalists take the existence of transaction costs in the goods market into account. There is an increasing body of theoretical literature stressing the importance of transactions costs in the goods markets as a source of non-linearity in the determination of the exchange rate (Dumas(1992), Sercu, Uppal and Van Hulle(1995), Obstfeld and Rogoff(2000)). The importance of transaction costs in the goods markets has also been confirmed empirically (Taylor, Peel, and Sarno(2001), Kilian and Taylor(2001)). In addition, it should also be remembered that a large component of most tradable goods has a local service component which increases the transaction costs in trading goods internationally (see Obstfeld and Rogoff(2000)).

We therefore introduce these transaction costs into the model and we assume that the fundamentalists behave differently depending on whether the exchange rate is within or outside the transaction costs band. When the exchange rate deviation from its fundamental value is larger than the costs of transacting goods and services, C, (assumed to be of the 'iceberg' type), the fundamentalists know that goods arbitrage will function, thereby driving the exchange rate towards its fundamental value. As a result, they will expect that the exchange rate will be driven to its fundamental value in the future. Thus, they use the forecasting rule as in equation 7. More formally, 
when $\left|s_{t}-s_{t}^{*}\right|>C$ holds, then equation 7 applies $^{3}$.

However, when the exchange rate deviations from the fundamental value are smaller than the transaction costs in the goods markets, fundamentalists know that there is no mechanism that drives the exchange rate towards its equilibrium value. As a result, fundamentalists expect the changes in the exchange rate to follow a white noise process and the best they can do is to forecast no change. More formally,

$$
\text { when } \quad\left|s_{t}-s_{t}^{*}\right|<C, \quad \text { then } \quad E_{t}^{f}\left(\Delta s_{t+1}\right)=0 \text {. }
$$

The chartists forecast the future exchange rate by extrapolating past exchange rate movements. Their forecasting rule can be specified as :

$$
E_{t}^{c}\left(\Delta s_{t+1}\right)=\beta \sum_{i=1}^{T} \alpha_{i} \Delta s_{t-i}
$$

Thus, the chartists compute a moving average of the past exchange rate changes and they extrapolate this into the future exchange rate change. The degree of extrapolation is given by the parameter $\beta$. Note that in contrast to the fundamentalists they take into account information concerning the fundamental exchange rate only indirectly, i.e. through the market exchange rate. In this sense they can be considered to be noise traders. In a way this chartist rule can also be seen as reflecting herding behaviour, i.e. chartists closely watch the movements of the exchange rate as a way to detect "market sentiments". If the latter are positive, they buy; if they are negative, they sell (Brunnermeier(2001)).

Our choice to give a prominent role to chartists' rules of forecasting is based on empirical evidence. The evidence that chartism is used widely to make forecasts is overwhelming (see Cheung and Chinn(1989), Taylor and Allen(1992)). It remains important, however, to check if the model is internally consistent. In particular, the chartists' forecasting rule must be shown to be profitable within the confines of the model. If these rules turn out to be unprofitable, they will not continue to be used. We return to this issue when we let the number of chartists be determined by the profitability of the chartists' forecasting rule.

We now analyse how fundamentalists and chartists evaluate the risk. The latter is measured by the variance terms in equation 6 , which we define as the weighted average of the squared (one period ahead) forecasting errors made by chartists and fundamentalists, respectively. Thus,

$$
\sigma_{i, t+1}^{2}=\sum_{k=1}^{\infty} \theta_{k}\left[E_{t-k}^{i}\left(s_{t-k+1}\right)-s_{t-k+1}\right]^{2}
$$

where $\theta_{k}=\theta(1-\theta)^{k}$ are geometrically declining weights $(0<\theta<1)$, and $i=c, f$

\footnotetext{
${ }^{3}$ Note that since $\psi<1$ market inefficiencies other than transaction costs continue to play a role when the exchange rate moves outside the transaction costs band. As a result, these inefficiencies prevent the exchange rate from adjusting instantaneously.
} 
However, fundamentalists and chartists perceive the risk in a different way. In particular the fundamentalists are assumed to take into account the deviation of the exchange rate from the fundamental in addition to the forecasting error. We will call the deviation of the market exchange rate from its fundamental, the misalignment. Thus the fundamentalists'risk term can be written as:

$$
\sigma_{f, t+1}^{2}=\frac{\sum_{k=1}^{\infty} \theta_{k}\left[E_{t-k}^{f}\left(s_{t-k+1}\right)-s_{t-k+1}\right]^{2}}{1+\left(s_{t}-s_{t}^{*}\right)^{2}}
$$

where $\left(s_{t}-s_{t}^{*}\right)$ is the misalignment.

The logic behind this specification is that the fundamentalists consider the fundamental exchange rate as a benchmark for computing their forecasted returns. At the same time, consistently with the way in which they forecast, fundamentalists take into account the fundamentals also when they have to evaluate the risk associated with their forecasted exchange rate. Therefore, the larger is the misalignment the less the fundamentalists will attach importance to the short term volatility as measured by the one-period ahead forecasting error. Put differently, as the misalignment increases, the fundamentalists become increasingly more confident that the exchange rate will revert to its fundamental value. As a result, their risk perception declines. In contrast, the misalignment does not affect the risk perception of the chartists. The reason is that the latter only take into account the past movements of the exchange rate to forecast the exchange rate. As a result, the fundamental exchange rate plays no (direct) role in this forecasting exercise. The logical implication is that the fundamental exchange rate does not play a (direct) role in determining the risk of the chartists either.

\subsection{Fitness of the rules}

The next step in our analysis is to specify how agents evaluate the fitness of these two forecasting rules. The general idea that we will follow is that agents use one of the two rules, compare their (risk adjusted) profitability ex post and then decide whether to keep the rule or switch to the other one. Thus, our model is in the logic of evolutionary dynamics, in which simple decision rules are selected. These rules will continue to be followed if they pass some "fitness" test (profitability test). Another way to interpret this is as follows. When great uncertainty exists about how the complex world functions, agents use a trial and error strategy. They try a particular forecasting rule until they find out that other rules work better. Such a trial and error strategy can be considered to be a rational strategy when agents cannot understand the full complexity of the underlying model.

In order to implement this idea we use the switching mechanism as proposed by Brock and Hommes(1997) which consists in making the weights of the 
forecasting rules a function of the relative profitability of these rules, i.e. ${ }^{4}$ :

$$
\begin{aligned}
& w_{c, t}=\frac{\exp \left[\gamma \pi_{c, t-1}^{\prime}\right]}{\exp \left[\gamma \pi_{c, t-1}^{\prime}\right]+\exp \left[\gamma \pi_{f, t-1}^{\prime}\right]} \\
& w_{f, t}=\frac{\exp \left[\gamma \pi_{f, t-1}^{\prime}\right]}{\exp \left[\gamma \pi_{c, t-1}^{\prime}\right]+\exp \left[\gamma \pi_{f, t-1}^{\prime}\right]}
\end{aligned}
$$

where $\pi_{c, t-1}^{\prime}$ and $\pi_{f, t-1}^{\prime}$ are the risk adjusted profits made by technical traders' and fundamentalists' forecasting the exchange rate in period $t-1$, i.e. $\pi_{c, t-1}^{\prime}=$ $\pi_{c, t-1}-\mu \sigma_{c, t-1}^{2}$ and $\pi_{f, t-1}^{\prime}=\pi_{f, t-1}-\mu \sigma_{f, t-1}^{2}$.

Equations 11 and 12 can be interpreted as follows. When the risk adjusted profits of the technical traders' rule increases relative to the risk adjusted net profits of the fundamentalists rule, then the share of agents who use technical trader rules increases in period $t$, and vice versa. The parameter $\gamma$ measures the intensity with which the technical traders (chartists) and fundamentalists revise their forecasting rules. With an increasing $\gamma$ agents react strongly to the relative profitability of the rules. In the limit when $\gamma$ goes to infinity all agents choose the forecasting rule which proves to be more profitable. When $\gamma$ is equal to zero agents are insensitive to the relative profitability of the rules. In the latter case the fraction of technical traders and fundamentalists is constant and equal to 0.5. Thus, $\gamma$ is a measure of inertia in the decision to switch to the more profitable rule ${ }^{5}$.

We depart from the Brock-Hommes switching mechanism in the way we define profits. Brock-Hommes define profits to be the total earnings on the optimal foreign asset holdings. We define the profits as the one-period earnings of investing $\$ 1$ in the foreign asset. More formally,

$$
\begin{aligned}
& \pi_{i, t}=\left[s_{t}\left(1+r^{*}\right)-s_{t-1}(1+r)\right] \operatorname{sgn}\left[\left(1+r^{*}\right) E_{t-1}^{i}\left(s_{t}-(1+r) s_{t-1}\right]\right. \\
& \text { where } \operatorname{sgn}[x]=\left\{\begin{array}{cc}
1 & \text { for } x>0 \\
0 & \text { for } x=0 \\
-1 & \text { for } x<0
\end{array} \text { and } i=c, f\right.
\end{aligned}
$$

Thus, when agents forecasted an increase in the exchange rate and this increase is realized, their per unit profit is equal to the observed increase in the exchange rate (corrected for the interest differential). If instead the exchange rate declines, they make a per unit loss which equals this decline (because in this case they have bought foreign assets which have declined in price).

\footnotetext{
${ }^{4}$ This specification of the decision rule is often used in discrete choice models. For an application in the market for differentiated products see Anderson, de Palma, and Thisse(1992). The idea has also been applied in financial markets by Brock and Hommes (1997). A variant of this rules was developed by Lux(1998).

${ }^{5}$ The psychological literature reveals that there is a lot of evidence of a "status quo bias" in decision making (see Kahneman, Knetsch and Thaler(1991). For this reason we will not set $\gamma=\infty$
} 
We use a concept of profits per unit invested for two reasons. First, our switching mechanism 11 and 12 selects the fittest rules. It does not select agents. To make this clear, suppose that chartists happen to have more wealth than fundamentalists so that their total profits exceeds the fundamentalists' profits despite the fact that the chartist rule happens to be less profitable (per unit invested) than the fundamentalist rule. In this case, our switching rule will select the fundamentalists rule although the agents who use this rule make less profits (because their wealth happens to be small) than agents using chartist rules. Second, in our definition of profits agents only have to use publicly available information, i.e. the forecasting rules and the observed exchange rate changes. They don't have to know their competitor's profits.

\section{Solution of the model}

In this section we investigate the properties of the solution of the model. We first study its deterministic solution. This will allow us to analyse the characteristics of the solution that are not clouded by exogenous noise. The model consists of equations (6) to (13) together with the transaction cost condition. In general, its non-linear structure does not allow for a simple analytical solution.

\subsection{The steady state}

We analyse the steady state of a simplified version of the model. For the sake of simplicity we assume that chartists only take one lag into account ${ }^{6}$. We also assume that transactions costs in the goods market are zero, i.e. $C=0$. In addition, we set $X=0$, and normalize the fundamental rate, $s_{t}^{*}=s^{*}=0$. We can then write equation 6 as follows:

$$
s_{t}=s_{t-1}-\Theta_{f, t} \psi s_{t-1}+\Theta_{c, t} \beta\left(s_{t-1}-s_{t-2}\right)
$$

where

$$
\Theta_{f, t}=\frac{w_{f, t} / \sigma_{f, t}^{2}}{w_{f, t} / \sigma_{f, t}^{2}+w_{c, t} / \sigma_{c, t}^{2}}
$$

and

$$
\Theta_{c, t}=\frac{w_{c, t} / \sigma_{c, t}^{2}}{w_{f, t} / \sigma_{f, t}^{2}+w_{c, t} / \sigma_{c, t}^{2}}
$$

are the risk adjusted weights of fundamentalists and chartists, and

$$
w_{f, t}=\frac{\exp \left[\gamma \pi_{f, t-1}-\mu \sigma_{f, t}^{2}\right]}{\exp \left[\gamma \pi_{c, t-1}-\mu \sigma_{c, t}^{2}\right]+\exp \left[\gamma \pi_{f, t-1}-\mu \sigma_{f, t}^{2}\right]}
$$

The equations 9 and 10 defining the variance terms can also be rewritten as follows:

$$
\sigma_{c, t}^{2}=(1-\theta) \sigma_{c, t-1}^{2}+\theta\left[E_{t-2}^{c}\left(s_{t-1}\right)-s_{t-1}\right]^{2}
$$

\footnotetext{
${ }^{6}$ One can easily add additional lags without altering the steady state analysis.
} 


$$
\sigma_{f, t}^{2}=(1-\theta) \sigma_{f, t-1}^{2}+\theta \frac{\left[E_{t-2}^{f}\left(s_{t-1}\right)-s_{t-1}\right]^{2}}{1+\left(s_{t-1}\right)^{2}}
$$

Using the definition of the forecasting rules 7 and 8 , this yields

$$
\begin{gathered}
\sigma_{c, t}^{2}=(1-\theta) \sigma_{c, t-1}^{2}+\theta\left[(1+\beta) s_{t-3}-s_{t-2}-s_{t-1}\right]^{2} \\
\sigma_{f, t}^{2}=(1-\theta) \sigma_{f, t-1}^{2}+\theta \frac{\left[(1-\psi) s_{t-2}-s_{t-1}\right]^{2}}{1+\left(s_{t-1}\right)^{2}}
\end{gathered}
$$

With suitable changes of variables it is possible to write the system as a 6-dimensional system. Set

$$
\begin{gathered}
u_{t}=s_{t-1} \\
x_{t}=u_{t-1}\left(=s_{t-2}\right)
\end{gathered}
$$

The 6 dynamic variables are $\left(s_{t}, u_{t}, x_{t}, \pi_{c, t}, \sigma_{c, t}^{2}, \sigma_{f, t}^{2}\right)$. The state of the system at time $t-1$, i.e. $\left(s_{t-1}, u_{t-1}, x_{t-1}, z_{t-1}, \pi_{c, t-1}, \sigma_{c, t-1}^{2}, \sigma_{f, t-1}^{2}\right)$ determines the state of the system at time $t$, i.e. $\left(s_{t}, u_{t}, x_{t}, \pi_{c, t}, \sigma_{c, t}^{2}, \sigma_{f, t}^{2}\right)$ through the following 6-D dynamical system:

$$
\begin{gathered}
s_{t}=\left[1+\beta-\Theta_{f, t}(\psi+\beta)\right] s_{t-1}-\left(1-\Theta_{f, t}\right) \beta u_{t-1} \\
u_{t}=s_{t-1} \\
x_{t}=u_{t-1} \\
\pi_{c, t}=\left(s_{t}-s_{t-1}\right) \operatorname{sgn}\left[\left(u_{t-1}+\beta\left(u_{t-1}-x_{t-1}\right)-s_{t-1}\right)\left(s_{t}-s_{t-1}\right)\right] \\
\sigma_{c, t}^{2}=(1-\theta) \sigma_{c, t-1}^{2}+\theta\left[(1+\beta) x_{t-1}-u_{t-1}-s_{t-1}\right]^{2} \\
\sigma_{f, t}^{2}=(1-\theta) \sigma_{f, t-1}^{2}+\theta \frac{\left[(1-\psi) u_{t-1}-s_{t-1}\right]^{2}}{1+\left(s_{t-1}\right)^{2}}
\end{gathered}
$$

where

$$
\Theta_{f, t}=\frac{w_{f, t} / \sigma_{f, t}^{2}}{w_{f, t} / \sigma_{f, t}^{2}+w_{c, t} / \sigma_{c, t}^{2}}
$$

and

$$
\begin{gathered}
w_{f, t}=\frac{\exp \left[\gamma \pi_{f, t-1}-\mu \sigma_{f, t}^{2}\right]}{\exp \left[\gamma \pi_{c, t-1}-\mu \sigma_{c, t}^{2}\right]+\exp \left[\gamma \pi_{f, t-1}-\mu \sigma_{f, t}^{2}\right]} \\
\pi_{f, t-1}=\left(s_{t-1}-u_{t-1}\right) \operatorname{sgn}\left[\left((1-\psi) x_{t-1}-u_{t-1}\right)\left(s_{t-1}-u_{t-1}\right)\right]
\end{gathered}
$$

A characteristics of the steady state is that the exchange rate is constant. As a result, the variance terms go to zero. This also implies that in the steady state, the risk adjusted weights of the fundamentalists and chartists are of the form $\Theta_{f, t}=\frac{\infty}{\infty}$ and $\Theta_{c, t}=\frac{\infty}{\infty}$. Rewriting these weights as follows: 


$$
\Theta_{f, t}=\frac{w_{f, t}}{w_{f, t}+w_{c, t}\left(\sigma_{f, t}^{2} / \sigma_{c, t}^{2}\right)}
$$

and

$$
\Theta_{c, t}=\frac{w_{c, t}\left(\sigma_{f, t}^{2} / \sigma_{c, t}^{2}\right)}{w_{f, t}+w_{c, t}\left(\sigma_{f, t}^{2} / \sigma_{c, t}^{2}\right)}
$$

One can show by numerical methods that in the steady state the expression $\sigma_{f, t}^{2} / \sigma_{c, t}^{2}$ converges to $1^{7}$. We show this in appendix 1 where we plot the ratio as a function of time in a typical simulation run. This implies that in the steady state $\Theta_{f, t}=w_{f, t}$ and $\Theta_{c, t}=w_{c, t}$. (Note that $\left.w_{f, t}+w_{c, t}=1\right)$.

The steady states of the system are now obtained by setting

$\left(s_{t-1}, u_{t-1}, x_{t-1}, \pi_{c, t-1}, \sigma_{f, t-1}^{2}, \sigma_{c, t-1}^{2}\right)=\left(s_{t}, u_{t}, x_{t}, \pi_{c, t}, \sigma_{f, t}^{2}, \sigma_{c, t}^{2}\right)=\left(\bar{s}, \bar{u}, \bar{x}, \bar{\pi}_{c}, \bar{\sigma}_{f}^{2}, \bar{\sigma}_{c}^{2}\right)$

in the dynamical system (22)-27).

There is a unique steady state where

$$
\bar{s}, \bar{u}, \bar{x}=0, \bar{\pi}_{c}=0, \bar{\sigma}_{f}^{2}, \bar{\sigma}_{c}^{2}=0
$$

Notice also that at the steady state

$$
\bar{w}_{c}=\frac{1}{2}, \bar{w}_{f}=\frac{1}{2}, \bar{\pi}_{f}=0
$$

i.e. the steady state is characterized by the exchange rate being at its fundamental level, by zero profits and zero risk, and by fundamentalist and technical trader fractions equal to $\frac{1}{2}$.

With this dynamical system it is not possible to perform the local stability analysis of the steady state with the usual techniques, based upon the analysis of the eigenvalues of the Jacobian matrix evaluated at the steady state. The reason is that the "map" whose iteration generates the dynamics is not differentiable at the steady state.

\subsection{Numerical analysis}

The strong non-linearities make an analysis of the model's global stability impossible. Therefore, we use simulation techniques which we will present in this and the following sections. We select " reasonable" values of the parameters, i.e. those that come close to empirically observed values. In appendix 2 we present a table with the numerical values of the parameters of the model and the lags involved. As we will show later, these are also parameter values for which the model replicates the observed statistical properties of exchange rate movements. We will also analyse how sensitive the solution is to different sets of parameter values. The dynamical model used in the numerical analysis is the same one as in the previous section except for the fact that $C>0$ and except for the number

\footnotetext{
${ }^{7}$ It does not appear to be possible to show this by analytical methods.
} 
of lags in the chartists' forecasting rule. We now return to the specification of the chartists's rule as given by equation (8). As a result, (14) becomes

$$
s_{t}=s_{t-1}-\Theta_{f, t} \psi s_{t-1}+\Theta_{c, t} \beta \sum_{i=1}^{T} \alpha_{i} \Delta s_{t-i}
$$

where $T=5$. Thus, the full model with all its lags is a 10-dimensional dynamic system.

We first concentrate on the fixed point solutions of the model. We find that for a relatively wide range of parameters the exchange rate converges to a fixed point (a fixed-point attractor). However, there are many such fixed points (attractors) to which the exchange rate converges depending on the initial conditions. We illustrate this feature in figure 1 where we plot the fixed point solutions (attractors) for the exchange rate as a function of the different initial conditions. These were obtained from simulating the model over 10000 periods. We found that after such a long period the exchange rate had stabilized to a fixed point (a fixed attractor). On the horizontal axis we set out the different initial conditions. These are initial shocks to the exchange rate in the period before the simulation is started ${ }^{8}$. The vertical axis shows the solutions for the exchange rate corresponding to these different initial conditions. Note the complex pattern of these fixed point solutions, with many discontinuities ${ }^{9}$. This has the implication that a small change in the initial condition can have a large effect on the solution. This feature lies at the heart of some of the results that are obtained with this model relating to the unpredictability of the effect of shocks in exogenous variables. We return to this phenomenon in section $7^{10}$.

It should also be noted that the fixed-point attractors lie within the transaction costs band. The intuition is that any fixed-point solution outside the transaction costs band would create an inconsistency, which can be described as follows. Outside the transaction costs band the fundamentalists' behaviour leads to a mean reverting process of the exchange rate, moving the latter towards the transaction costs band. Thus, if a fixed point solution were observed outside the transactions cost band, this would mean that the fundamentalists would fail to move the exchange rate towards the band. Once inside the band, the fundamentalists' dynamics disappears. The only dynamics then comes from the chartists who drive the exchange rate to some attractor within the band. The exact position of this attractor depends on the entry point of the exchange rate in the transactions cost band, and this depends on the initial shock.

\footnotetext{
${ }^{8}$ There are longer lags in the model, i.e. five Thus we set the exchange rate with a lag of more than one period before the start equal to 0 . This means that the initial conditions are one-period shocks in the exchange rate prior to the start of the simulation. All the other lagged dynamic variables are set equal to 0 when the simulation is started.

${ }^{9}$ With a high value of $\gamma$ results are qualitatively similar.

${ }^{10}$ The numerical values of the simulations are shown in appendix 2 .
} 


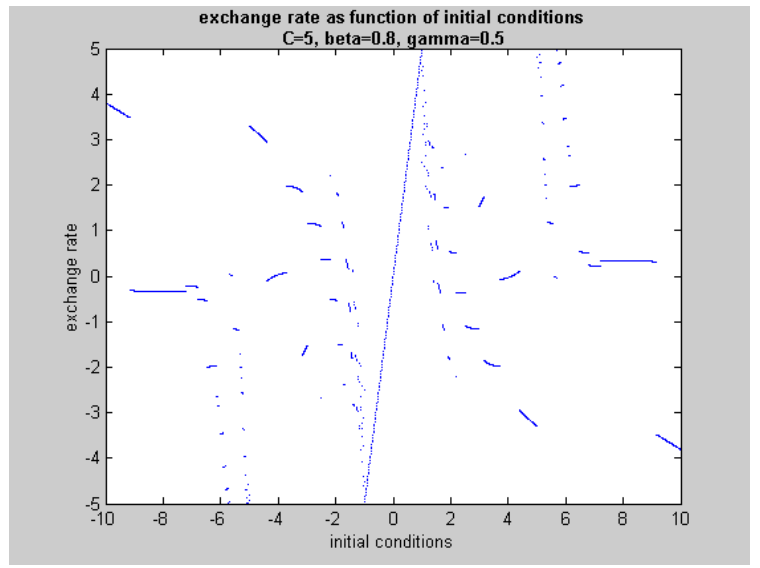

Figure 1:

\section{Sensitivity analysis}

In this section we perform a sensitivity analysis. We do this by showing bifurcation diagrams that relate the solutions to different values of important parameters of the model. We concentrate on the extrapolation parameter used by the chartists, $\beta$, on the sensitivity of the switching rule, $\gamma$, and on transactions costs $C$.

\subsection{Sensitivity with respect to $\beta$}

The left panel of figure 2 shows an example of such a bifurcation diagram. On the horizontal axis we set out different values of the extrapolation parameter $\beta$. On the vertical axis we show the solutions for the exchange rate. This is the exchange rate obtained after 10000 periods, given an initial shock to the exchange rate ${ }^{11}$. We observe the following. For low values of $\beta$ we obtain unique fixed point solutions. When $\beta$ reaches a value of approximately 0.9 , we enter the chaotic region. This is characterised by infinitely many solutions for each value of $\beta$. These points correspond to strange attractors within which the exchange rate then travels.

Figure 2 (left panel) only provides a visual indication of the existence of a chaotic region. One can detect the existence of chaos more rigourously by calculating the largest Lyapunov exponent. This measures the rate of divergence of nearby trajectories. A positive largest Lyapunov exponent indicates chaos (see Rosenstein, et al. (1992) and De Grauwe, et al. (1993) for a discussion of Lyapunov exponents). Since we have access to the equations generating chaos (and thus we know the dimension of the system) it is relatively simple to estimate

\footnotetext{
${ }^{11}$ The initial shock in the one period lagged exchange rate was +2 . All the other lagged
} dynamical variables were set to 0 . 
the largest Lyapunov exponent. It is given by the following expression:

$$
\lambda_{1}(i)=\frac{1}{T-1} \sum_{t=1}^{T-1} \ln \frac{d_{t}(i)}{d_{t}(0)}
$$

where $d_{t}(i)$ is the (Euclidian) distance between the $t^{\text {th }}$ pair of nearby trajectories after $i$ iterations, and $d_{t}(0)$ is the reinitialized distance at each point $\mathrm{t}^{12}$. We have set $i=1$ which is a conservative measure, i.e. we compute the distance at each iteration. We show the results of computing the largest Lyapunov exponents in figure 2 (right panel). The latter confirms the visual impression of the left panel of figure 2, i.e. for values of $\beta$ exceeding 0.9 the largest Lyapunov exponent becomes positive. The exact value of $\beta$ at which this happens depends on the other parameters of the model and on the initial conditions. Note also that for values of $\beta$ below 0.9 we obtain a Lyapunov exponent which is zero. This result is due to the coexistence of fixed point attractors. In the absence of chaos (e.g. when $\beta=0.8$ and $\gamma=0.5$ ) we obtain one separate fixed point for each initial condition (see figure 1). This means that when computing the Lyapunov exponent for two nearby trajectories we will find that these trajectories keep a constant distance in the steady state. As a result, the largest Lyapunov exponent must be zero.

The importance of the initial conditions in determining whether the exchange rate will enter the chaotic domain is illustrated in Figure 3 on the left panel, where we fix $\beta=0.9$ and vary the initial conditions. The left panel of figure 3 is constructed in the same way as figure 1 and shows the steady state exchange rate (attractor) as a function of the initial value of the exchange rate (initial conditions) while the right panel exhibits the corresponding Lyapunov exponents. We now observe that the different initial conditions lead to switches in and out of the chaotic region. This feature suggests that there are attractors (some fixed points, others strange attractors) located in different basins of attraction. The border line between these different basins is itself complex. As a result, small differences in the intial conditions can lead the system towards different attractors some of which are fixed point attractors, others chaotic attractors.

These features illustrate the great complexity in the exchange rate dynamics. As will be analysed in greater detail later, this complexity has many different implications. It acts as a veil obscuring the transmission of exogenous shocks (e.g. shocks in the fundamental exchange rate) into the market exchange rate. It has the potential of producing regime switches triggered by small disturbances. Finally, this complexity greatly complicates the making of standard statistical inferences from the distribution of the exchange rate changes.

\subsection{Sensitivity with respect to $\gamma$}

In this section we analyse the sensitivity of the solutions with respect to changes in the parameter $\gamma$ which measures the sensitivity of the switiching rules with

\footnotetext{
${ }^{12}$ Note that since we have a 10-dimensional system the distance between the two nearby trajectories is computed as the (Euclidian) distance of the 10 variables at each point $t$.
} 

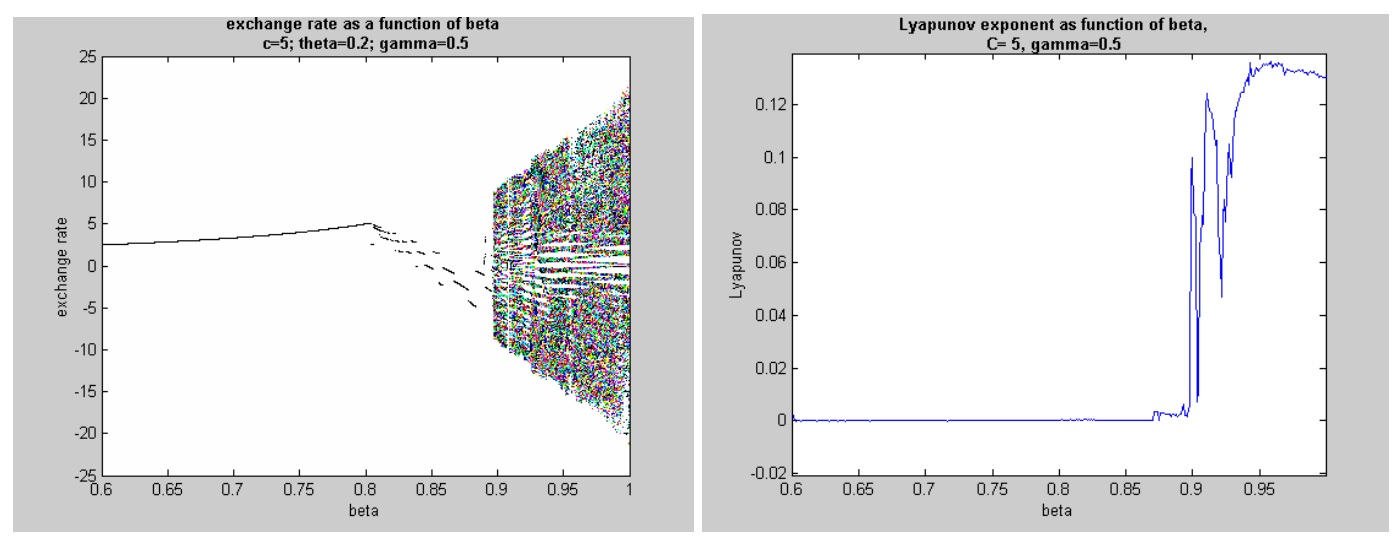

Figure 2:
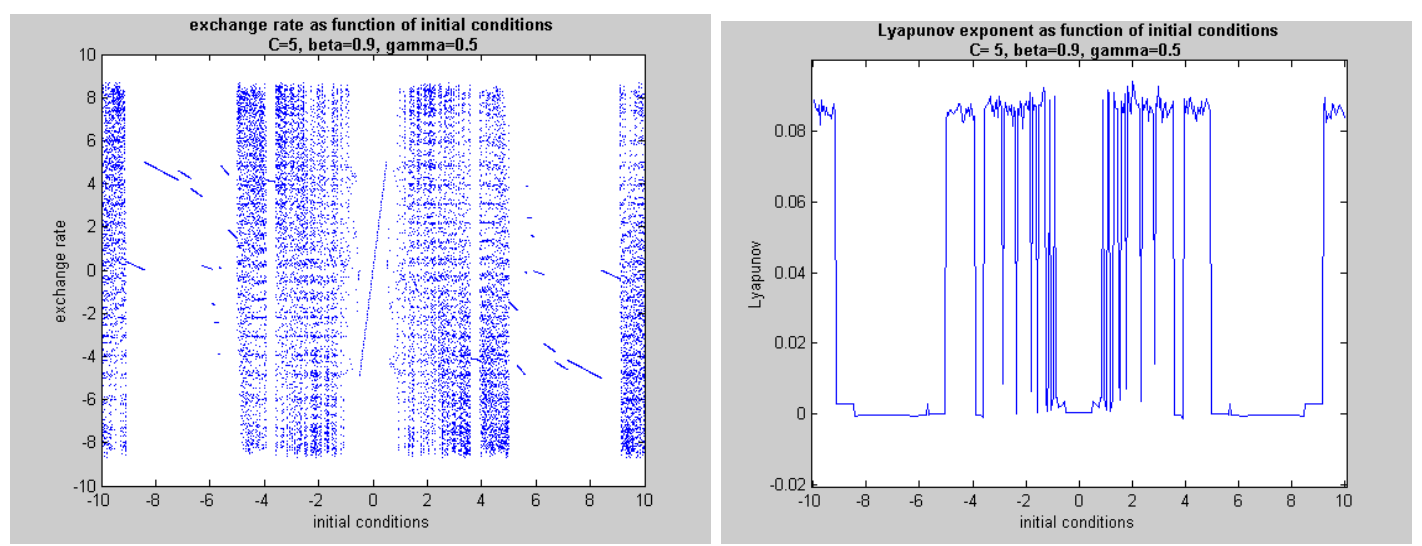

Figure 3: 
respect to profits ("intensity of choice"). We show the results in figures 4 (a) and (b) for two different values of the extrapolation parameter, $\beta$. When $\beta$ is sufficiently low $(\beta=0.8$ ) we obtain fixed point solutions for all values of $\gamma$ (figure $4(\mathrm{a}))$. When $\beta=0.9$ which as we have seen in the previous section, constitutes the boundary value between fixed point and chaotic solution, variations in $\gamma$ lead the solutions to switch in and out of chaos (figure 4(b)). The latter is also confirmed by the Lyapunov exponents shown in figure 4(c). Thus, changing $\gamma$ produces similar effects as changing the initial conditions. Note, however, that for small values of $\gamma$ we obtain fixed point solutions.

\subsection{Sensitivity with respect to transactions costs}

We also investigated the importance of transaction costs. In order to do so, we produced similar bifurcation diagrams as in the previous sections. We now set out the transactions costs on the horizontal axis while we fix $\beta$ and $\gamma$. As in the previous case, we find that when $\beta$ is sufficiently smaller than 0.9 we obtain fixed point solutions for all values of the transactions costs ${ }^{13}$. In figure 4(d) we show the case of $\beta=0.9$. We observe switching in and out of chaos. This is confirmed by figure $4(\mathrm{e})$ which shows the largest Lyapunov exponents for the same values of the transaction costs. Note that as transactions costs increase the spread of the possible solutions increases.

The empirical evidence in favour of deterministic chaos is not very strong. Sometimes deterministic chaos has been detected in the data, but most often no such dynamics has been found (D. Guillaume (2000), C. Schittenkopf, G. Dorffner and E. Dockner (2001)). Therefore, we will focus the analysis of the model on parameter values that do not lead to deterministic chaos. We will show that in combination with stochastic shocks this model is capable of producing a dynamics that exhibits many of the features of chaotic dynamics despite the fact that the deterministic solutions of the model are fixed points. In addition in section 6 we will calibrate the model in such a way that it reproduces the main statistical properties of exchange rate movements. It will be shown that the parameters that mimick these statisitical properties best do not produce deterministic chaos.

\section{The stochastic version of the model}

We now introduce stochastic disturbances to the model. In our model these disturbances appear in that we assume that the fundamental exchange rate behaves as a random walk, i.e. $s_{t}^{*}=s_{t-1}^{*}+\epsilon_{t}$, where $\epsilon_{t}$ is iid with mean $=0$ and standard deviation $=0.1$.

We simulate the model with a combination of parameter values that we refer to as the "standard case". This includes setting $\mathrm{c}=5, \beta=0.9$ and $\psi=0.2$. and $\gamma=0.5$. See also the table in appendix 2 for the other parameters. (Similar

\footnotetext{
${ }^{13}$ We do not show this bifurcation diagram here. It can be obtained from the authors.
} 


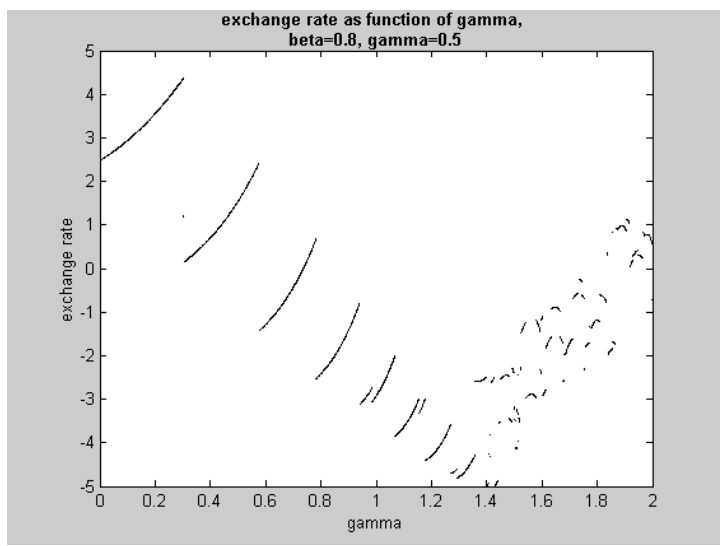

(a)

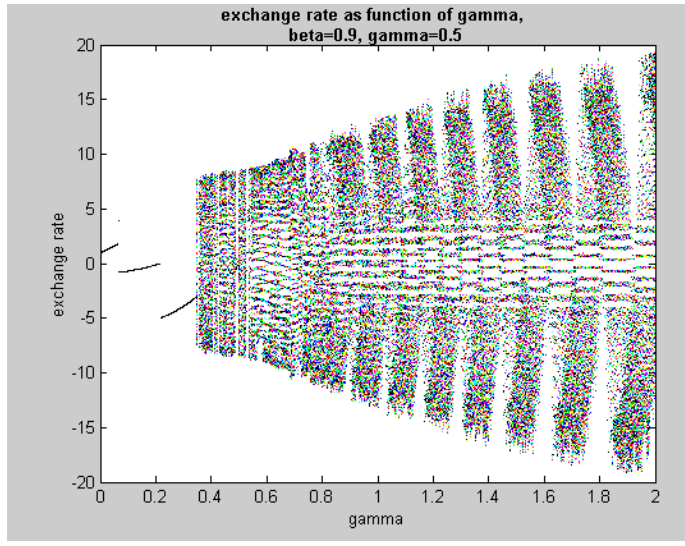

(b)

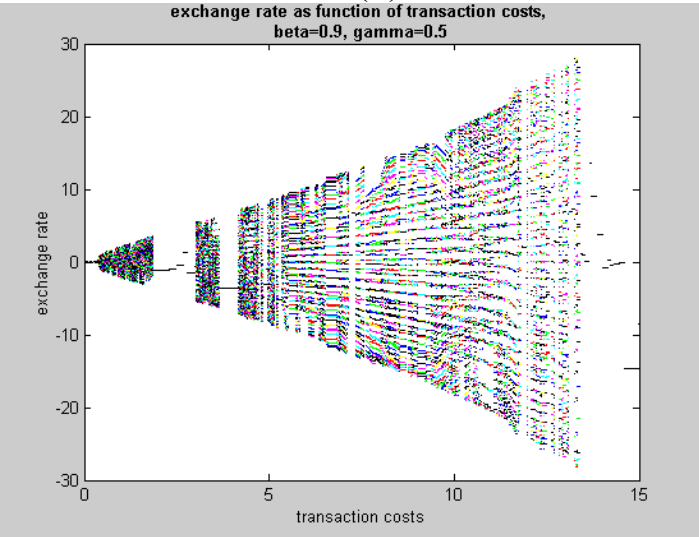

(d)

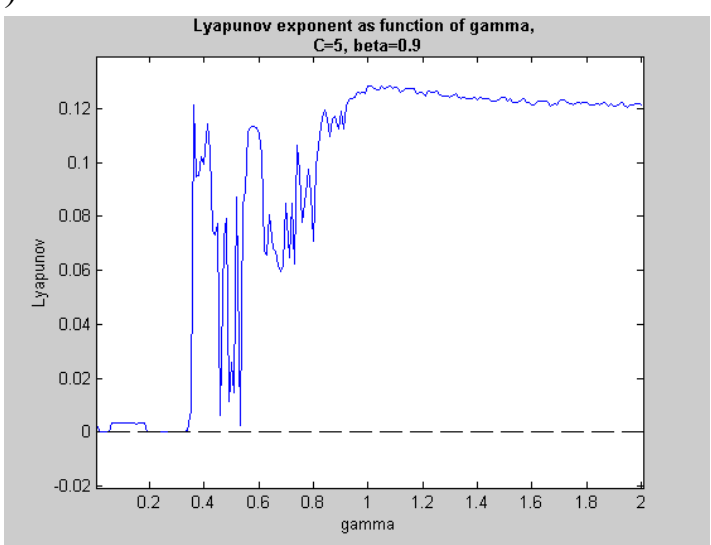

(c)

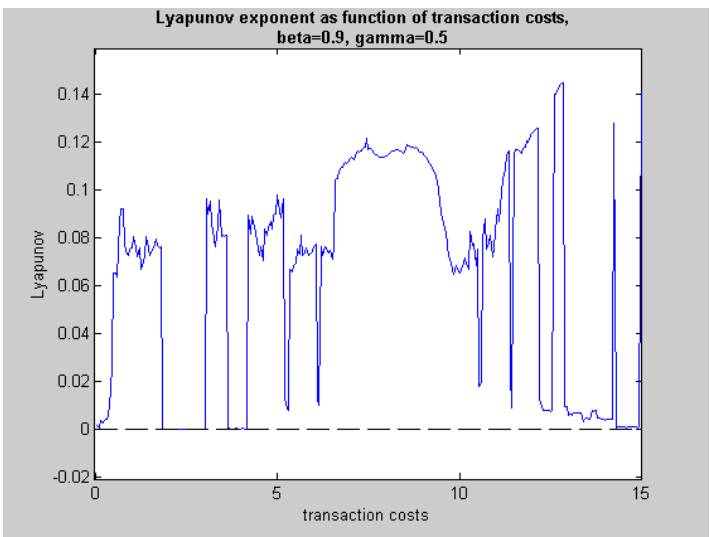

(e)

Figure 4: 
results are obtained for a wide range of parameter values. In addition, it will be shown in section 6 that these parameter values reproduce the statistical properties observed in exchange rate movements).

A first feature of the solution of the stochastic version of the model is the sensitivity to initial conditions. In order to show this, we first simulated the model with the "standard" parameter values and then we simulated the model with the same parameters setting but with a slightly different initial condition, i.e. $s_{0}=+3$, and $s_{0}=+3.01$. In both cases we used identical stochastic disturbances driving the fundamental. We show the time paths of the (market) exchange rate in figure $5(\mathrm{a})$.

We observe that after a certain number of periods the two exchange rates start following a different path. This result is related to the presence of many fixed-point attractors in the deterministic part of the model, which are themselves dependent on the initial conditions (see figure 1 which shows how slight differences in initial conditions can lead to fixed-point attractors that are very far apart). As a result, the two exchange rates can substantially diverge because they are attracted by fixed-points that are located in different basins of attraction. The nice aspect of this is that we obtain a result that is typical for chaotic systems, however, without chaos being present in the deterministic part of the model. The combination of exogenous noise and a multiplicity of fixed-point attractors located in different basins of attraction creates sensitivity to initial conditions, a feature which is also found in chaotic dynamics.

A second feature of the model relates to the way shocks in the fundamental exchange rate are transmitted into the market exchange rate. In linear models a permanent shock in the fundamental has a predictable effect on the exchange rate, i.e. the coefficient that measures the effect of the shock in the fundamental on the exchange rate converges after some time to a fixed number. Things are very different in our non-linear model. We illustrate this by showing how a permanent increase in the fundamental is transmitted to the exchange rate. We assumed that the fundamental rate increases by 10 , and we computed the effect on the exchange rate by taking the difference between the exchange rate with the shock and the exchange rate without the shock. In a linear model we would find that in the long run the exchange rate increases by 10 . This is not the case in our model. We present the evidence in figure 5(b) where we show the effect of the same permanent shock of 10 in the fundamental rate on the exchange rate. The simulations are done assuming exactly the same stochastics in the scenario with as without the permanent shock in the fundamental exchange rate. Thus, there is no exogenous noise in the model that could blur the transmission process from the fundamental rate to the exchange rate.

The most striking feature of these results is that the effect of the permanent shock does not converge to a fixed number. In fact, it follows a complex pattern. Thus, in a non-linear world it is very difficult to predict what the effect will be of a given shock in the fundamental, even in the long run. Such predictions can only be made in a statistical sense, i.e. our model tells us that the effect of a shock of 10 in the fundamental will be to increase the exchange rate by 10 on average. In any given period, however, the effect could deviate substantially 
from this average prediction.

The importance of the initial conditions for the effect of a permanent shock in the fundamental can also be seen by the following experiment. We simulated the same permanent shock in the fundamental but applied it in two different time periods. In the first simulation we applied the shock in the first period; in the second simulation we applied it in the next period. The exogenous noise was identical in both simulations. Thus, the only difference is in the timing of the shock. We show the results in figure 5(c).

We observe that the small difference in timing changes the future history of the exchange rate. As a result, the effect of the shock measured at a particular point in time can be very different in both simulations. Thus history matters. The time at which the permanent shock occurs influences the effects of the shock.

Our results help to explain why in the real world it appears so difficult to predict the effects of changes in the fundamental exchange rate on the market rate, and why these effects seem to be very different when applied in different periods. In fact this is probably one of the most intriguing empirical problems. Economists usually explain the difficulty of forecasting the effects of a particular change in one exogenous variable (e.g. an expansion of the money stock) by invoking the ceteris paribus hypothesis., i.e. there are usually other exogenous variables changing unexpectedly, preventing us to isolate the effect of the first exogenous variable. In our model the uncertainty surrounding the effect of a disturbance in an exogenous variable is not due to the failure of the ceteris paribus hypothesis. No other exogenous variable is allowed to change. The fact is that the change in the exogenous variable occurs at a particular time, which is different from all other times. This difference is due, among others, to the fact that at each point in time there is a different composition of chartists and fundamentalists in the market, which itself is due to different past performances of chartists and fundamentalists forecasting rules. As a result, the same fundamental shock applied at different time periods is "perceived" differently in the market, e.g. at one moment there are fewer fundamentalists than at another moment so that the same fundamental shock gets less attention. Thus, initial conditions (history) matters to forecast the effect of shocks. Since each initial condition is unique, it becomes impossible to forecast the precise effect of a shock at any given point in time.

Finally, it should be stressed that the uncertainty about the effect of a permanent shock in the fundamental only holds in a particular environment that is related to a low variance of the noise. In a later section we will analyse how different environments concerning the variance of shocks affect the results.

\section{Empirical relevance of the model}

In this section we analyse how well our model replicates the empirical anomalies and puzzles that have been uncovered by the empirical literature. We calibrate the model such that it replicates the observed statistical properties of exchange 


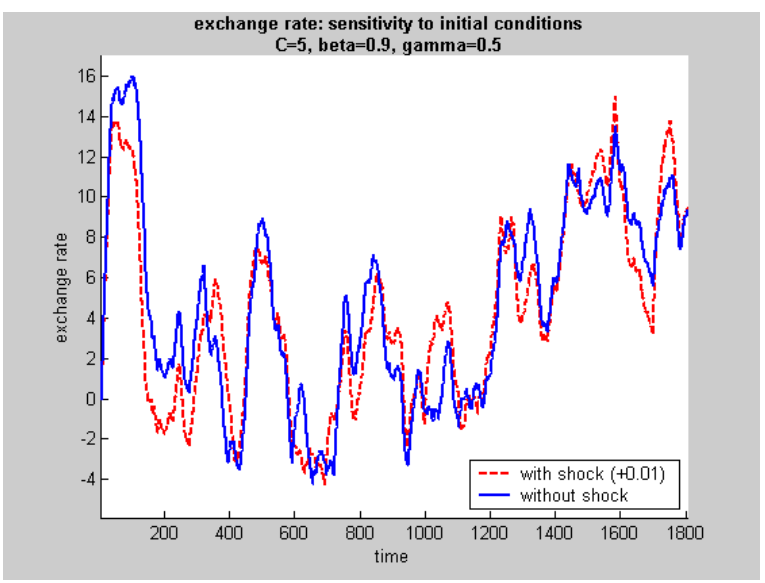

(a)

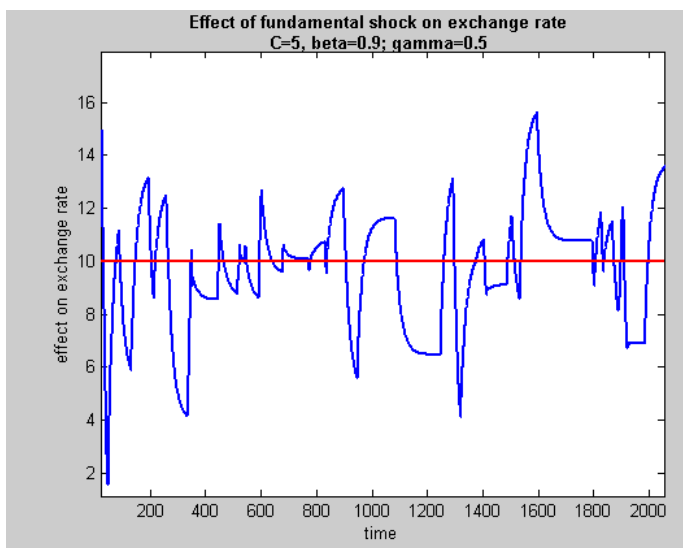

(b)

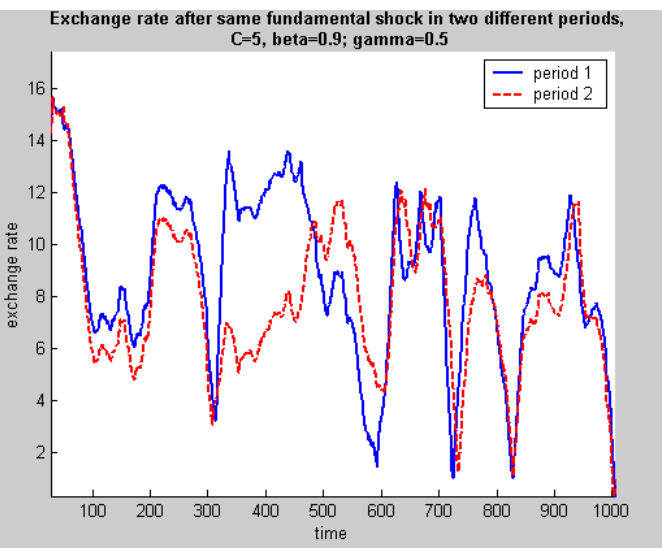

(c)

Figure 5: 
rate movements. The parameters of the model that do this are those that we used in the previous sections. As was noted there, typically these are parameter sets that do not produce deterministic chaos. All the simulations reported in this section are stochastic in that the fundamental is driven by a random walk as specified in the previous section. We start with the 'disconnect puzzle'.

\subsection{The disconnect puzzle}

The "disconnect" puzzle was popularized by Obstfeld and Rogoff(2000). It states that the exchange rate is disconnected from its underlying fundamentals most of the time ${ }^{14}$. It was first analysed by John Williamson(1985) who called it the 'misalignment problem'. This puzzle was also implicit in the celebrated Meese and Rogoff studies of the early 1980s documenting that there is no stable relationship between exchange rate movements and the news in the fundamental variables. Goodhart (1989) and Goodhart and Figlioli (1991) found that most of the changes in the exchange rates occur when there is no observable news in the fundamental economic variables. This finding contradicted the theoretical models (based on the efficient market hypothesis), which imply that the exchange rate can only move when there is news in the fundamentals.

We simulated our model to check whether it can replicate this empirical regularity. In figure 6 we show the market exchange rate and the fundamental rate for a combination of parameters that does not produce deterministic chaos. (Our results hold equally well for a large set of parameter values). As described before, the fundamental rate is driven by a random walk. We observe that the market rate can deviate from the fundamental value substantially and in a persistent way. Moreover, it appears that the exchange rate movements are often disconnected from the movements of the underlying fundamental, and that they often move in opposite directions. The previous evidence is impressionistic. In order to show the nature of the disconnect phenomenon in a more precise way we applied a cointegration analysis to the simulated exchange rate and its fundamental using the same parameter values as in figure 6 for a sample of 8000 periods. We found that there is a cointegration relationship between the exchange rate and its fundamental. Note that in our setting there is only one fundamental variable. This implies that no bias from omitted variables can occur.

In the next step we specify a EC model in the following way:

$$
\Delta s_{t}=\eta\left(s_{t-1}-\delta s_{t-1}^{*}\right)+\sum_{i=1}^{n} \vartheta_{i} \Delta s_{t-i}+\sum_{i=1}^{n} \phi_{i} \Delta s_{t-i}^{*}
$$

The first term on the right hand side is the error correction term. The result of estimating this equation is presented in table 1 where we have set $n=4$. We

\footnotetext{
${ }^{14}$ In its original formulation the disconnect puzzle has two dimensions. One says that the exchange rate is disconnected from its fundamental. The second dimension relates to the fact that real variables (for example, the trade account) do not react to the changes in the exchange rate. In this paper we only analyse the first dimension.
} 


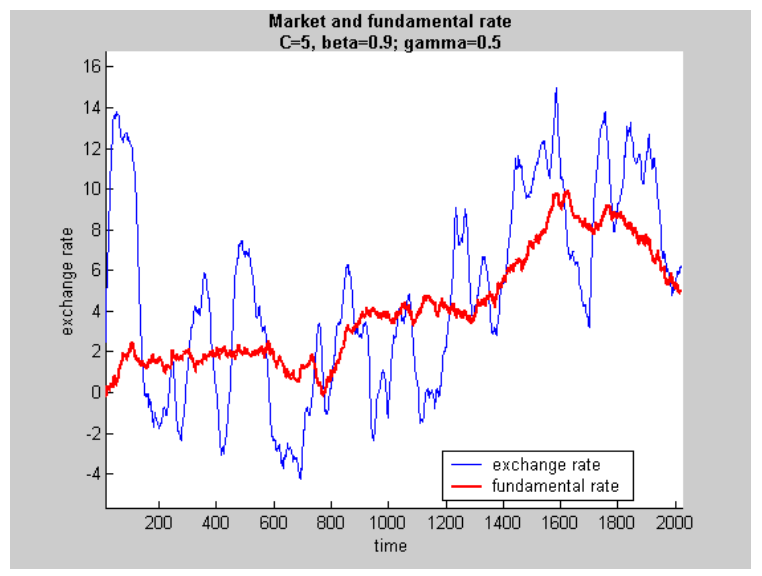

Figure 6:

find that the error correction coefficient $(\eta)$ is very low. This suggests that the mean reversion towards the equilibrium exchange rate takes a very long time. In particular, only $0.3 \%$ of the adjustment takes place each period. It should be noted that in the simulations we have assumed that fundamentalists estimate the speed of adjustment in the goods market $(\psi)$ to be 0.2 . Thus, based on their belief about the speed of adjustment in the goods market they expect the exchange rate to have a speed of adjustment towards its equilibrium of $20 \%$ in each period. However, the nominal exchange rate is considerably slower to adjust towards its equilibrium than what is implied by the estimated speed of adjustment in the goods market. This slow adjustment of the nominal exchange rate is due to the chartists' extrapolation behaviour. This phenomenon has been observed in reality. Chen et al.(2002) have recently discovered that most of the slow mean reversion of the real exchange rate is due to slow adjustment of the nominal exchange rate and not of the goods prices.

From table 1, we also note that the changes in fundamentals have a small and insignificant impact on the change in exchange rate. In contrast, the past changes in the exchange rate play a significant role in explaining the change in exchange rate. These results are consistent with the empirical findings using VAR approach, which suggests that the exchange rate is driven by its own past $(\text { see De } \operatorname{Boeck}(2000))^{15}$.

Thus, our model generates an empirical regularity (the 'disconnect' puzzle) that is widely observed in reality. We can summarise the features of this puzzle as follows. First, over the very long run the exchange rate and its fundamentals

\footnotetext{
${ }^{15}$ We also performed a cointegration analysis for shorter sample periods (1000 periods). We find that in some sample periods the exchange rate and its fundamental are cointegrated, in other sample periods we do not find cointegration. This is in line with the empirical evidence indicating that in some periods the exchange rate seems to be disconnected from its fundamental while in other periods it tightly follows the fundamentals .
} 
Table 1: error correction model

\begin{tabular}{|c|c|c|c|c|c|c|c|c|c|}
\hline \multicolumn{2}{|c|}{ Error correction } & \multicolumn{6}{|c|}{$\boldsymbol{\Delta} \mathbf{s}_{t-i}$} & \multicolumn{4}{|c|}{$\boldsymbol{\Delta} \mathbf{s}_{t-i}^{*}$} \\
\hline$\eta$ & $\delta$ & $\vartheta_{1}$ & $\vartheta_{2}$ & $\vartheta_{3}$ & $\vartheta_{4}$ & $\varphi_{1}$ & $\boldsymbol{\varphi}_{2}$ & $\boldsymbol{\varphi}_{3}$ & $\boldsymbol{\varphi}_{4}$ \\
\hline-0.003 & 0.92 & 0.32 & 0.20 & 0.13 & 0.08 & 0.03 & 0.02 & 0.01 & 0.01 \\
-5.9 & 4.9 & 22.8 & 13.7 & 8.7 & 5.9 & 1.9 & 1.0 & 0.6 & 0.1 \\
\hline
\end{tabular}

are cointegrated. However, the speed with which the exchange rate reverts to its equilibrium value is very slow. Second, in the short run the exchange rate and its fundamentals are "disconnected", i.e. they do not appear to be cointegrated. Our model closely mimics these empirical regularities.

\subsection{The "excess volatility" puzzle}

In this section we discuss another important empirical regularity, which has been called the "excess volatility" puzzle, i.e. the volatility of the exchange rate by far exceeds the volatility of the underlying economic variables. Baxter and Stockman (1989) and Flood and Rose (1995) found that while the movements from fixed to flexible exchange rates led to a dramatic increase in the volatility of the exchange rate no such increase could be detected in the volatility of the underlying economic variables. This contradicted the 'news' models that predicted that the volatility of the exchange rate can only increase when the variability of the underlying fundamental variables increases ( see Obstfeld and Rogoff (1996) for a recent formulation of this model).

In order to deal with this puzzle we compute the noise to signal ratio in the simulated exchange rate. We derive this noise to signal ratio as follows:

$$
\operatorname{var}(s)=\operatorname{var}(f)+\operatorname{var}(n)
$$

where $\operatorname{var}(s)$ is the variance of the simulated exchange rate, $\operatorname{var}(f)$ is the variance of the fundamental and $\operatorname{var}(n)$ is the residual variance (noise) produced by the non-linear speculative dynamics which is uncorrelated with $\operatorname{var}(f)$. This the noise is to be interpreted as the volatility of the exchange rate which is unrelated to the volatility of the underlying fundamental variable. Rewriting (36) we obtain

$$
\frac{\operatorname{var}(n)}{\operatorname{var}(f)}=\frac{\operatorname{var}(s)}{\operatorname{var}(f)}-1
$$

The ratio $\operatorname{var}(n) / \operatorname{var}(f)$ can be interpreted as the noise to signal ratio. It gives a measure of how large the noise produced by the non-linear dynamics is with respect to the exogenous volatility of the fundamental exchange rate. A noise to signal ratio exceeding 1 means that the total volatility of the exchange rate is dominated by volatility which is unrelated to fundamental volatitlity. We simulate this noise to signal ratio for different values of the extrapolation parameter $\beta$ (see figure $7(\mathrm{a})$ ). Each of these noise to signal ratios is computed using simulations of 1000 periods. We find that with increasing $\beta$ the noise to 
signal ratio increases. This implies that when the chartists increase the degree with which they extrapolate the past exchange rate movements, the noise in the exchange rate, which is unrelated to fundamentals, increases. Thus, the signal about the fundamentals that we can extract from the exchange rate becomes more clouded when the chartists extrapolate more. It is important to note that since the fundamental variable follows a random walk, its variance increases with the length of the time interval over which it is computed ${ }^{16}$. We, therefore, also checked how the noise to signal ratio depends on the length of the time interval. We show the results in figure $7(\mathrm{~b})$ where we present the noise-to-signal ratios as a function of the lenght of time over which they are computed. We find that when the time horizon increases the noise-to-signal ratio declines. This is so because over long time horizons most of the volatility of the exchange rate is due to the fundamentals' volatility and very little to the endogenous noise. In contrast, over short time horizons the endogenous volatility is predominant and the signal that comes from the fundamentals is weak. This is consistent with the empirical finding concerning misalignments we discussed before.

It is also important to relate the noise-to-signal ratio to transaction costs in the goods market. Therefore we show in figure 7(c) how the noise-to-signal ratio changes with the size of transaction costs. We observe that the noise-to-signal ratio increases significantly with the size of transaction costs. An interpretation of this result is that as transaction costs increases the mean-reverting force from fundamentalists is weak while the chartists' force is strong. Thus the noise created by chartists increases and clouds the signal coming from fundamentals.

\subsection{Non-normality of the returns}

It is a well-established empirical fact that returns in financial markets are not normally distributed, exhibiting more density around the mean and fatter tails than the normal. This phenomenon was first discovered by Mandelbrot (1963) in commodity markets. Since then, fat tails and excess kurtosis have been discovered in many other asset markets including the exchange market. In particular, in the latter the returns have a kurtosis typically exceeding 3 and a measure of fat tails (Hill index) ranging between 2 and 5 (see Koedijk, Stork and de Vries (1992), de Vries(2001), Huisman, et al.(2002)). It implies that most of the time the exchange rate movements are relatively small but that occasionally periods of turbulence occur with relatively large exchange rate changes. However, it has also been detected that the kurtosis is reduced under time aggregation. This phenomenon has been observed for most exchange rates (Lux(1998), Calvet and Fisher(2002)). We checked whether this is also the case with the simulated exchange rate changes in our model.

We computed the kurtosis and the Hill index of the simulated exchange rate returns for different parameter values of the model using simulation runs of 2000 periods. The Hill index was computed for 4 different samples of 2000 iterations

\footnotetext{
${ }^{16}$ In the limit when $t \rightarrow \infty \operatorname{var}(f) \rightarrow \infty$.
} 


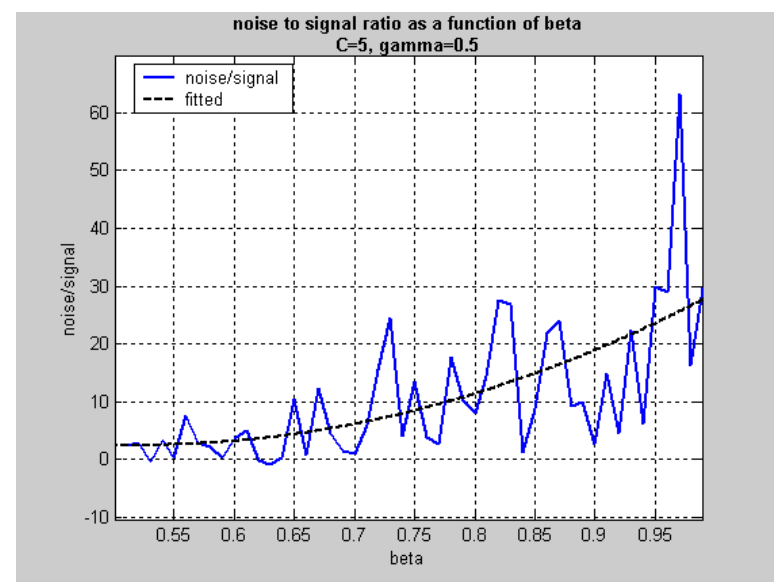

(a)

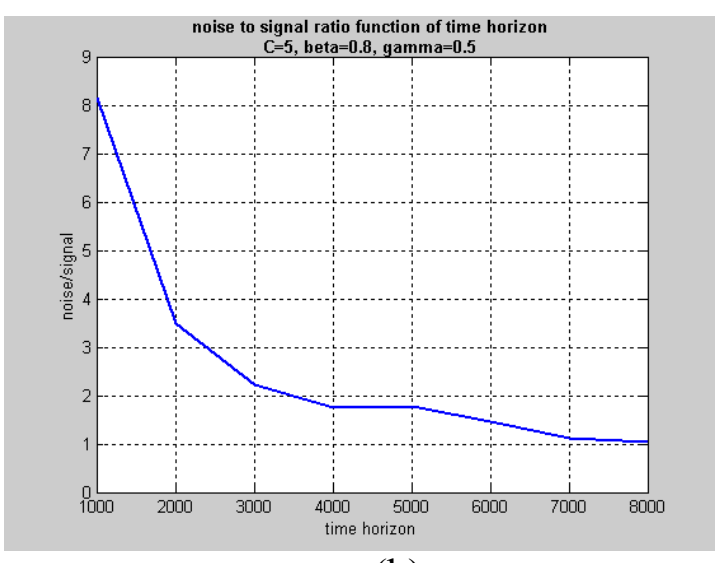

(b)

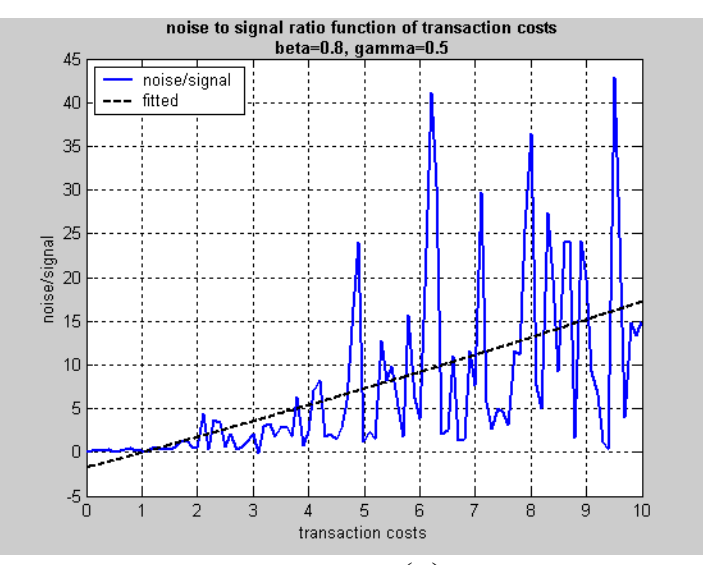

(c)

Figure 7: 
Table 2: Kurtosis and Hill index

\begin{tabular}{|l|c|c|c|c|}
\hline \multirow{2}{*}{ Parameter values } & kurtosis & & \multicolumn{3}{|c|}{ median Hill index } \\
\cline { 3 - 5 } & & $\mathbf{2 . 5 \%}$ tail & $\mathbf{5 \%}$ tail & $\mathbf{1 0 \%}$ tail \\
\hline $\mathrm{C}=5, \beta=0.9, \gamma=0.5$ & 5.65 & 4.92 & 4.98 & 3.98 \\
$\mathrm{C}=5, \beta=0.9, \gamma=1$ & 4.39 & 4.06 & 4.46 & 3.90 \\
$\mathrm{C}=5, \beta=0.9, \gamma=5$ & 6.30 & 4.42 & 3.00 & 2.40 \\
$\mathrm{C}=5, \beta=0.8, \gamma=0.5$ & 8.33 & 4.39 & 4.19 & 3.80 \\
$\mathrm{C}=5, \beta=0.8, \gamma=1$ & 7.92 & 4.15 & 4.37 & 3.73 \\
$\mathrm{C}=5, \beta=0.8, \gamma=5$ & 11.08 & 3.63 & 3.90 & 3.54 \\
\hline
\end{tabular}

Table 3: Kurtosis and time aggregation

\begin{tabular}{|l|c|c|c|c|}
\cline { 1 - 4 } Parameter values & $\begin{array}{l}1 \text { period } \\
\text { returns }\end{array}$ & $\begin{array}{l}10 \text { period } \\
\text { returns }\end{array}$ & $\begin{array}{l}25 \text { period } \\
\text { returns }\end{array}$ & $\begin{array}{l}50 \text { period } \\
\text { returns }\end{array}$ \\
\cline { 1 - 4 } $\mathrm{C}=5, \beta=0.9, \gamma=0.5$ & 5.65 & 5.96 & 3.17 & 3.08 \\
$\mathrm{C}=5, \beta=0.9, \gamma=1$ & 4.39 & 4.11 & 3.67 & 3.45 \\
$\mathrm{C}=5, \beta=0.9, \gamma=5$ & 6.30 & 2.77 & 2.15 & 2.19 \\
\cline { 1 - 1 } $\mathrm{C}=5, \beta=0.8, \gamma=0.5$ & 8.33 & 8.52 & 3.14 & 3.43 \\
\cline { 1 - 1 } $\mathrm{C}=5, \beta=0.8, \gamma=1$ & 7.92 & 7.39 & 3.28 & 3.30 \\
\cline { 1 - 1 } $\mathrm{C}=5, \beta=0.8, \gamma=5$ & 11.08 & 10.14 & 3.46 & 3.05 \\
\hline
\end{tabular}

and we selected the median value. In addition, we considered three different cut-off points of the tails $(2.5 \%, 5 \%, 10 \%)$. We show the results of the kurtosis and of the Hill index in table 2. We find that for a broad range of parameter values the kurtosis exceeds 3 and the Hill index indicates the presence of fat tails. Finally we check if the kurtosis of our simulated exchange rate returns declines under time aggregation. In order to do so, we chose different time aggregation periods and we computed the kurtosis of the time-aggregated exchange rate returns. We found that the kurtosis declines under time aggregation. In table 3 we show the results for some sets of parameter values ${ }^{17}$. This suggests that the non-linear dynamics of the model transforms normally distributed noise in the fundamental exchange rate into exchange rate movements with tails that are significantly fatter than the normal distribution and with more density around the mean. Thus our model mimics an important empirical regularity. It should be noted that similar models with heterogenous agents applied to the stock markets have been equally successful in replicating fat tails and excess kurtosis (see Lux and Marchesi(1999, 2000), Kirman and Teysierr(2000), LeBaron, et al. (1999), and Gaunersdorfer and Hommes(2000)).

\footnotetext{
${ }^{17}$ Another empirical regularity of the distribution of exchange returns is its symmetry. We computed the skewness, and we could not reject that the distribution is symmetric.
} 


\section{$7 \quad$ Large and small shocks}

In linear models the size of the shocks does not affect the nature of the dynamics. In non-linear models the size of the shocks matters. In order to illustrate this in our model, we simulated it under two different assumptions about the variance of the shocks in the fundamental exchange rate. In the first case we assume low variance of these shocks, in the second case we assume a high variance (ten times higher), i.e.

low variance : $s_{t}^{*}=s_{t-1}^{*}+\epsilon_{t}$, where $\epsilon_{t} \sim$ iid , mean $=0$ and standard deviation $=0.1$

high variance : $s_{t}^{*}=s_{t-1}^{*}+\epsilon_{t}$, where $\epsilon_{t} \sim$ iid, mean $=0$ and standard deviation $=1$

The results of our simulations are presented in figure 8. (The simulations shown here are representative for a wide range of parameter values).

Two conclusions follow from a comparison of the low and high variance cases. First, in the low variance case we observe sustained deviations from the fundamental exchange rate; this is not the case when the fundamental exchange rate is subject to large shocks (compare upper-left with lower-left panel in figure $8)$. Second, the sensitivity to small changes in initial conditions is clearly visible when the variance of the exchange rate is low (see upper-righ panel). When this variance is high, no such sensitivity can be observed (see lower-right panel). It is important to stress that the transactions cost band is the same in both cases. Thus, when the shocks are small relative to the given band of transactions costs, the movements of the exchange rate show more complexity than when the shocks are large.

The previous results are confirmed by a cointegration analysis like the one we performed in section 6.1 (see table 1) where this analysis refers to a low variance environment. We show the results for the high variance regime in table 4. These results contrast with those obtained in table 1 . The error correction coefficient is much larger in the high variance regime of table 4 than in the low variance regime of table 1 . In the high variance case $9 \%$ of the deviation from equilibrium is adjusted for per period. This constrasts with a $0.3 \%$ found in the low variance case (see table 1 ).

As in the low variance case we also performed a cointegration analysis over shorter sample periods. The results contrast with the low variance case. For sample periods of 1000 we find that the exchange rate and its fundamentals are always cointegrated. In the low variance case we do not find cointegration for all these sub-samples.

These results confirm what we observed from figure8, i.e. that in a regime of high variance of shocks the exchange rate is more tightly linked to the fundamentals, and that the speed of adjustment towards the equilibrium is higher than in low variance regimes.

The intuition of this result is that when the fundamental shocks are small the exchange rate regularly switches from the dynamics inherent within the transactions cost band to the one prevaling outside the band. This non-linearity produces a lot of noise and complexity in the dynamics of the exchange rate. 
When the shocks are large relative to transactions cost band the dynamics outside the band mostly prevails, leading to a tighter link between the exchange rate and the fundamental. This feature has also been found to hold empirically. In particular, it has been found that the PPP-relationship holds much tighter in high inflation countries than in low inflation countries (See De Grauwe and Grimaldi(2001)). Put differently, in high inflation countries the link between the exchange rate and one of its most important fundamentals is tighter than in low inflation countries.

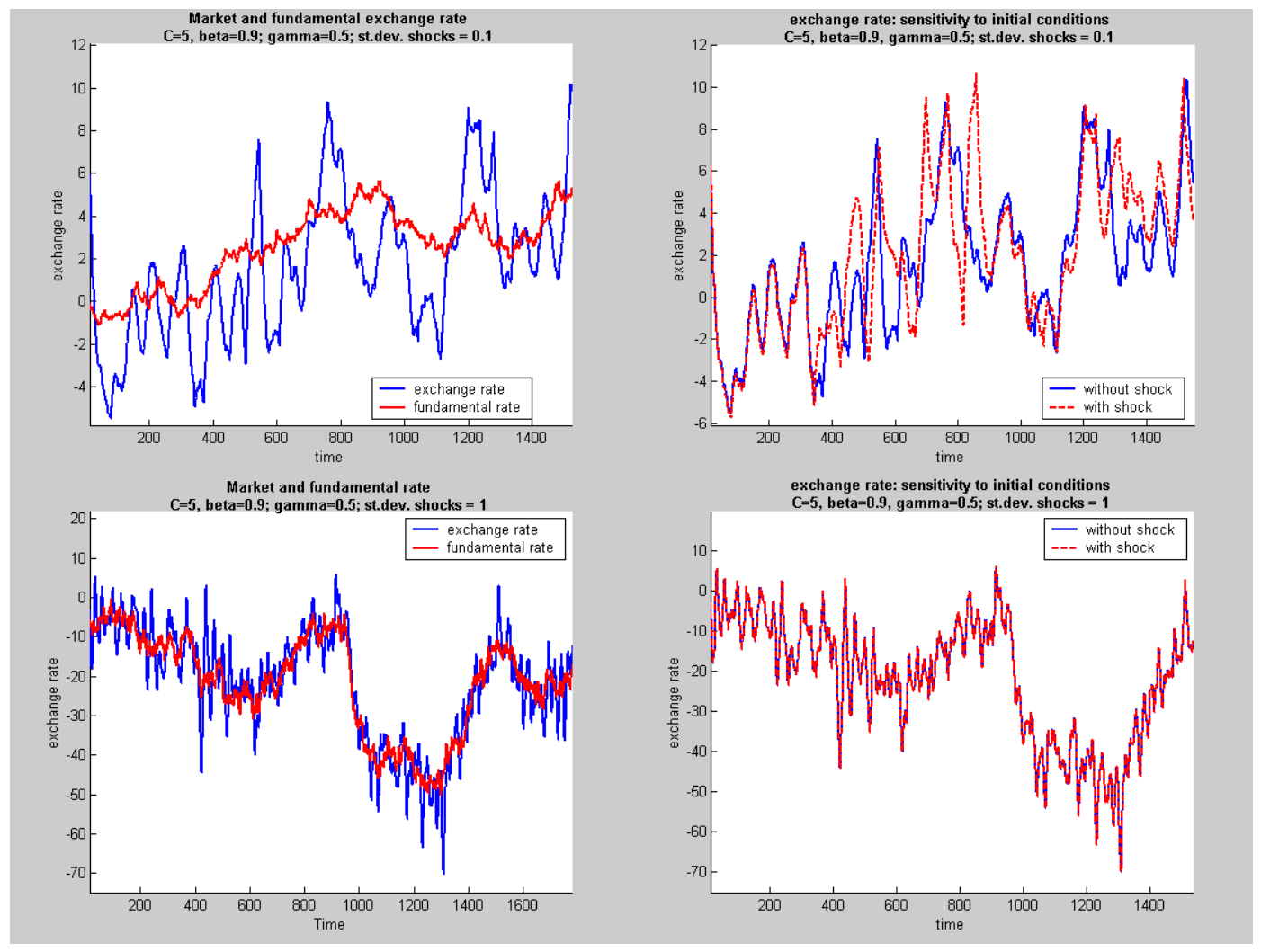

Figure 8:

\section{On the success of technical analysis}

There is a large literature showing that technical analysis is used widely in the foreign exchange market, also by large players (see (Taylor and Allen (1992), Wei and Kim (1997), James (2003)). This suggests that technical analysis (chartism) is profitable. Does our model replicate the empirical evidence of the success of 
Table 4: error correction model high variance

\begin{tabular}{|c|c|c|c|c|c|c|c|c|c|}
\hline \multicolumn{2}{|c|}{ Error correction } & \multicolumn{5}{|c|}{$\Delta \mathbf{s}_{t-i}$} & \multicolumn{4}{|c|}{$\mathbf{s}_{t-i}^{*}$} \\
\hline$\eta$ & $\delta$ & $\vartheta_{1}$ & $\vartheta_{2}$ & $\vartheta_{3}$ & $\vartheta_{4}$ & $\varphi_{1}$ & $\varphi_{2}$ & $\varphi_{3}$ & $\varphi_{4}$ \\
\hline-0.09 & 1.002 & 0.36 & 0.19 & 0.09 & 0.07 & 0.05 & 0.01 & 0.00 & -0.01 \\
-24.2 & 156.2 & 27.5 & 13.2 & 6.7 & 5.1 & 3.3 & 0.9 & 0.06 & -0.8 \\
\hline
\end{tabular}

chartism?

We investigate this issue by analysing how chartism evolves under different conditions. In figure 9, left panel, we show the average chartists' weight for increasing values of the intensity of choice parameter $\gamma$ in two different environments concerning the variance of the shocks in fundamentals. We obtained the chartists weights by simulating the model over 10000 periods and computing the average weight over the last 5000 periods. Our first finding is that chartism does not disappear, i.e. in all simulations for many different parameters configurations we find that the weight attached to chartists never goes to zero. On the contrary, we find that the chartists weight fluctuates around a market share, which exceeds $50 \%$. (Note that in the steady state of the model the chartists' and fundamentalists' weights are 50\%). These results are consistent with the empirical evidence of the importance of chartism in foreign exchange market. Second, the market share of chartists increases with the parameter $\gamma$ which measures the intensity with which agents react to the relative profitability of the two rules. This result is related to the fact that increases in $\gamma$ increase the volatility of the exchange rate. The increase in volatility is what chartists thrive on. Third, we find that, in general, chartism is more profitable in the low variance environment than in the high variance environment ${ }^{18}$. This is due to the fact that in a low variance environment the exchange rate movements are disconnected from the fundamental most of the time making fundamentalist forecasting relatively unattractive. We show this feature in the right panel of figure 9 which presents the average realized profits of chartists and fundamentalists in the low variance environment. It is striking to see that in such an environment chartism appears to be much more profitable than fundamentalism.

From the preceding analysis we conclude that chartism is generally more profitable than fundamentalism. In addition, there is a positive correlation between turbulence (noise) and the share of chartism in the market. With more noise there is more chartist profit and thus there are more chartists. The reverse is also true: with more chartists there is more noise and thus more profits for chartists. These results suggests that there is a selffulfilling evolutionary dynamics present in the system which can be described as follows. As the chartists increase in numbers, the noise they create makes the use of chartists rules more profitable. At the same time, the chartists have the effect of "creating smoke around the fundamentals", making fundamentalists' forecasting less profitable. Another way to interpret this result is that chartism creates noisy information that becomes the source of profitable speculation. The more chartists there are

\footnotetext{
${ }^{18}$ We defined low and high variance environments in the previous section
} 

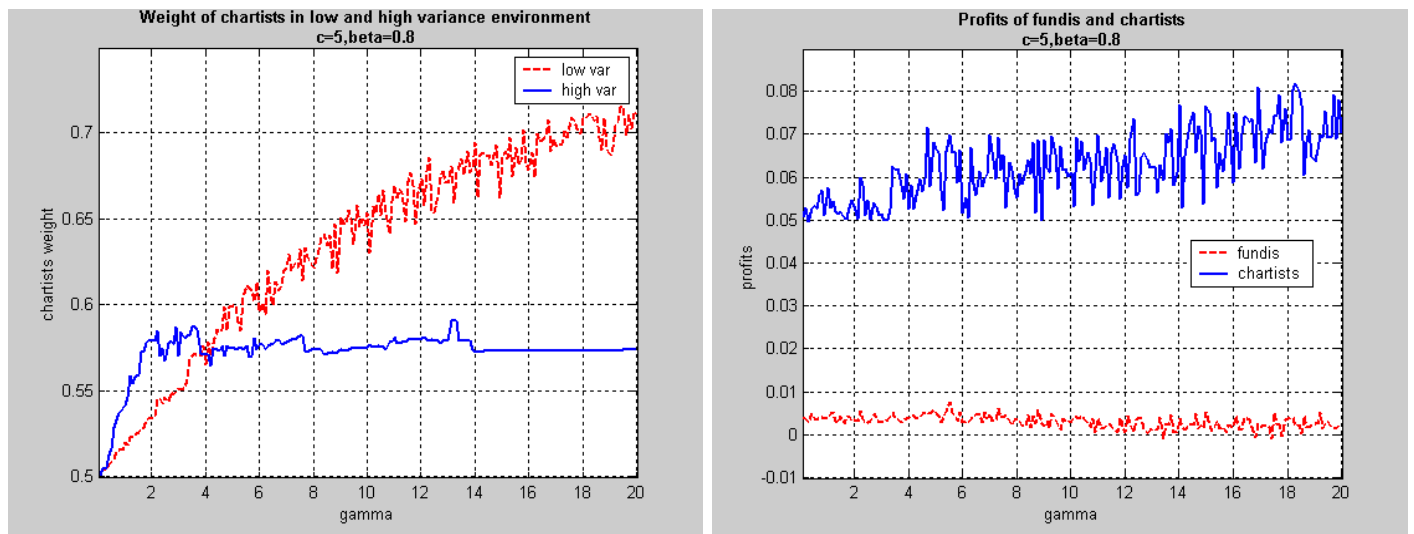

Figure 9:

the more such information is created and the more profitable chartists' forecasting becomes. Thus, chartists create an informational environment which makes it rational to use chartists' rules.

Why doesn't all this not lead to a corner solution, i.e. a situation in which chartists drive out all fundamentalists? As we have seen in the previous paragraphs, the share of the chartists in the market is not driven to 1 , it always settles below 1 . The reason has to do with risk. When the weight of chartists increases in the market, so does volatility. Thus, as the weight of chartists in the market increases, both profitability and risk of using chartist rules increase. The increasing risk is strong enough to prevent the chartists from completely driving out the fundamentalists and taking over the market.

\section{Conclusion}

Using a mean variance optimisation framework we developed a simple non linear exchange rate model with transactions costs and with heterogeneous agents. Transactions costs in the goods markets produce an important non-linearity in the model. Agents are heterogenous in that they have different beliefs, i.e. they use different forecasting rules. The relative importance of these different types of agents is driven by the relative profitability of their forecasting rules and by the risk associated with the use of such rules. Thus agents are rational in the sense that they evaluate ex post the relative (risk-adjusted) profitability of the forecasting rules and switch to the better one. We argued that this trial and error process is a better way to model agents' behaviour than to assume that their expectations are rational. In rational expectations models with heterogenous agents the burden of collecting and processing information for individual agents is extraordinarily high, requiring God-like capacities. Not only must individual agents know the structure of the model, but they must also be able to read 
the minds of all the other agents. In traditional religions agents with such intellectual capacities were called Gods.

The model generates a multitude of fixed-point attractors depending on the initial conditions, i.e. for each initial condition there is a unique solution. By adding exogenous noise the model produces a complex dynamics that resembles a chaotic dynamics, although the deterministic part of the model is not chaotic. This feature has interesting implications. First, there is sensitivity to initial conditions, which implies that a small disturbance can drive the exchange rate on a different path. Second, the effect of a permanent shock in the fundamental exchange rate has a complex structure that might even be chaotic. This implies that the effect of a permanent shock in the fundamentals is largely unpredictable, i.e. one cannot forecast how the shock will affect the exchange rate in any particular point of time, but one can predict the average effect. We also find that the effect of such a shock depends on the exact timing of its occurrence. Thus, history matters. The market has a memory. This contrasts with exchange rate models based on the efficient market and rational expectations assumptions that tend to be a-historical.

The quality of a model should be judged by its empirical performance. We argued that the traditional rational expectations efficient market model has failed empirically. We analyse to what extent our model is capable of reproducing the exchange rate puzzles observed in reality. The first puzzle we analyse is the "disconnect puzzle" which has to do with the fact that the exchange rate movements are disconnected, most of the time, from the movements of the underlying fundamental variables. In our model "disconnection" is a natural outcome of the complex dynamics produced by the interactions between agents using different pieces of information.

Closely related to the disconnect puzzle is the presence of excess volatility of the exchange rate compared to the volatility of its fundamentals. This feature has been widely documented in the empirical literature. Our model mimicks this feature. We find that it is connected to the number of chartists in the market, i.e. the greater the share of chartists the larger is the noise to signal ratio in exchange rate movements.

Third, our model generates fat tails and excess kurtosis, a phenomenon which has been observed in exchange rate returns, and more generally in returns in most financial markets.

Fourth, the empirical evidence suggests that in environments with high variance of the fundamentals (e.g. in high inflation countries) the link between exchange rate changes and its fundamentals (e.g. inflation rates) is tighter than in low variance environments. We also obtain such a result in our model. This implies that in high variance environments predicting exchange rate changes using fundamental information should be easier than in low variance environments.

Finally, we found that chartism is a profitable strategy and often tends to dominate the market. This result is consistent with the empirical evidence of the importance of chartism in foreign exchange markets. We also detected a self-fullfilling character of chartist profitability, i.e.when more chartists enter the 
market they create more noise and thereby make chartists rules more profitable, inducing more entry. Another way to interpret this result is that chartism creates noisy information that becomes the source of profitable speculation. Thus, chartists create an informational environment which makes it rational to use chartists' rules. This process is stopped, however, because of increasing risk generated by the increased noise that the same chartists produce. The selffulfilling nature of chartists' profitability allows us to understand why chartism is generally observed to be important in foreign exchange markets. 


\section{References}

Bacchetta, P. and van Wincoop E., 2003, Can information heterogeneity explain the exchange rate determination puzzle?, NBER working paper 9498.

Baxter, M., Stockman, 1989, A., "Business Cycles and the Exchange Rate Regime. Some International Evidence", Journal of Monetary Economics, 23, may $377-400$.

Brock, W., and Hommes, C., 1997, A rational route to randomness, Econometrica, 65, 1059-1095

Brock, W., and Hommes, C.,1998, Heterogeneous beliefs and routes to chaos in a simple asset pricing model, Journal of Economic Dynamics and Control, $22,1235-1274$.

Brunnermeier, M., 2001, Asset pricing under asymmetric information, Oxford University Press.

Cheung Y. and Lai K., 2000. " On the purchasing power parity puzzle". Journal of International Economics, 52 .

Cheung Y., Lai K. and Bergman M., 2001, " Dissecting the PPP puzzle: the unconventional roles of nominal exchange rate and price adjustments". Paper presented at CES-Ifo Conference Munich 2002.

Chiarella, C., Dieci, R., Gardini, 2002, L., "Speculative behaviour and complex asset price dynamics", Journal of Economic Behaviour and Organisation.

Copeland, L., 2000, Exchange Rates and International Finance, 3rd ed., Prentice Hall.

De Boeck J., 2000. "The effect of macroeconomic 'news' on exchange rates: a structural VAR approach" mimeo University of Leuven.

De Grauwe, P. , Dewachter, H., and Embrechts, 1993, M., Exchange Rate Theories. Chaotic Models of the Foreign Exchange Markets, Blackwell.

De Grauwe, P., and Grimaldi, M., 2001, "Exchange Rates, Prices and Money: A Long Run Perspective", International Journal of Finance and Economics, 6, no. 4, pp. 289-314.

De Grauwe, P., and Vansteenkiste, I., 2001," Exchange Rates and Fundamentals. A Non-linear Relationship?", CESifo Working Paper, no. 577, October.

de Vries, C., 2000, "Fat tails and the history of the guilder", Tinbergen Magazine, 4, Fall, pp. 3-6.

De Long, J., Bradford, B., Schleiffer and Summers, L., 1990, "Noise Trader Risk in Financial Markets", Journal of Political Economy.

Dornbusch R., 1976, "Expectations and exchange rate dynamics", Journal of Political Economy 84.

Dumas B., 1992, "Dynamic equilibrium and the real exchange rate in a spatially separated world", Review of financial studies 5 (2), 153-180.

Engel C., 2000, " Long run PPP may not hold after all", Journal of International Economics, 57. 
Engel C. and Morley J., 2001, "The adjustment of prices and the adjustment of the exchange rate", Discussion paper, Department of Economics, University of Wisconsin.

Evans, M., and Lyons, R., 1999, "Order Flow and Exchange Rate Dynamics", NBER Working Paper, no. 7317.

Faust, J., Rogers, J., Swanson, E., and Wright, J., 2002, dentifying the Effects of Monetary Policy Shocks on Exchange Rates Using High Frequency Data, International Finance Discussion Papers, no. 739, Board of Governors of the Federal Reserve System, Washington, D.C.

Flood, R, and Rose, A., 1995, "Fixing the Exchange Rate Regime: A virtual Quest for Fundamentals", Journal of Monetary Economics, 36, August, 3-37.

Frankel, J., and Froot, K., 1986, "The Dollar as a Speculative Bubble: A Tale of Fundamentalists and Chartists", NBER Working Paper, no. 1963.

Gaunersdorfer, A., and Hommes, C., 2000, A nonlinear structural model for volatility clustering, CeNDEF working paper 00-02, University of Amsterdam.

Gaunersdorfer, A., Hommes, C., and Wagener, F., 2003, Bifurcation Routes to Volatitlity Clustering, CeNDEF working paper 03-03, University of Amsterdam.

Goodhart, C., 1989, "News and the Foreign Exchange Market", LSE Financial Markets Group Discussion paper, 71.

Goodhart, C., and Figliuoli, L., 1991, "Every Minute Counts in the Foreign Exchange Markets", Journal of International Money and Finance, 10, 23-52.

Guillaume D., 2000 , Intradaily Exchange Rate Movements, Kluwer Academic Publishing.

Hallwood, P., MacDonald, R., 1994, International Money and Finance, 2nd ed., Blackwell, Oxford.

Huisman, R., Koedijk, K., Kool, C., and Palm, F., 2002, The tail-fatness of FX returns reconsidered, in De Economist, 150, no. 3, September, 299-312.

Hommes, C., Financial markets as nonlinear adaptive evolutionary systems, Quantitative Finance 1, 149-167.

Isard, P., 1995, Exchange Rate Economics, Cambridge University Press.

James, J., 2003, Simple trend-following strategies in currency trading, Quantitative Finance, vol.3, no.4.

Johansen, S., 1991, Estimation and Hypothesis Testing of Cointegration Vectors in Gaussian Vector Autoregressive Models, Econometrica, 55, 1551-80.

Kilian L. and M. Taylor, 2001, "Why is it So Difficult to Beat the Random Walk Forecast of Exchange Rates?" Mimeo, University of Warwick, pp. 29.

Kirman, A., and Teyssière, G., 2000, Microeconomic models for long memory in the volatility of financial time series, GREQAM, working paper DT 00A31, Marseille.

Kurz, M., 1994, "On the Structure and Diversity of Rational Beliefs", Economic Theory, 4, 877-900.

Kurz, M., and Motolese, M., 2000, "Endogenous Uncertainty and Market Volatility", mimeo, Stanford University.

LeBaron, B., Arthur, W., and Palmer, R., 1999, Time series properties of an 
artificial stock market, Journal of Economic Dynamics and Control, 23, 14871516.

LI K., 1999, "Testing symmetry and proportionality in PPP : A panel data approach", Journal of Business and Economic Statistics 17 (4) , 409-418.

Lux T., 1998, "The socio-economic dynamics of speculative markets: interacting agents, chaos, and fat tails of return distributions", Journal of Economic Behaviour and Organisation, vol.33.

Lux T., Marchesi M., 2000, "Volatility clustering in financial markets: a microsimulation of interacting agents", International Journal of Theoretical and Applied Finance.

Lyons, R., 2001, The Microstructure Approach to Exchange Rates, MIT Press, Cambridge, Mass.

Mandelbrot, B., 1963, The variation of certain speculative prices, The Journal of Business, University of Chicago, 36, 394-419.

Meese, R., and Rogoff, 1983, "Empirical Exchange Rate Models of the Seventies: Do they Fit Out of Sample?", Journal of International Economics, 14, 3-24.

Michael P., Nobay R., and Peel A., 1997, "Transaction costs and non-linear adjustment in real exchange rates: an empirical investigation", Journal of Political Economy 105 (4), 862-879.

Obstfeld, M. and Rogoff, K., 1996, Foundations of International Macroeconomics, MIT Press, Cambridge, Mass.

Obstfeld, M., and Rogoff, K., 2000, "The Six Major Puzzles in International Macroeconomics: Is there a Common Cause?", NBER Working Paper no. 7777, July.

Rogoff, K., 1996, "The purchasing power parity puzzle", Journal of Economic Literature, 34, June, 647-668.

Schittenkopf C., Dorffner G., Dockner E.,2001, "On nonlinear, stochastic dynamics in economics and financial time series", Studies in Nonlinear Dynamics and Econometrics 4(3), pp. 101-121.

Shleifer, A., 2000, Introduction to Behavioural Finance, Clarendon Press.

Taylor, M., and Allen, H., 1992, "The Use of Technical Analysis in the Foreign Exchange Market", Journal of International Money and Finance, 11, $304-14$.

Taylor M., Peel D., and Sarno L., 2001, "Non-linear mean reversion in real exchange rates: towards a solution to the purchasing power parity puzzles", CEPR discussion paper no 2658.

Wei Shang-Jin and Kim Jungshik 1997. "The big players in the foreign exchange market:do they trade on information or noise?". NBER working paper 6256 .

Williamson, J., 1985, "The Exchange Rate System", Policy Analyses in International Economics, 5, Institute for International Economics, Washington, D.C. 


\section{A Appendix 1: The variance ratio $\sigma_{f, t}^{2} / \sigma_{c, t}^{2}$ in steady state}

In this appendix we show the ratio of the variance of the fundamentalist and chartists $\sigma_{f, t}^{2}$ and $\sigma_{c, t}^{2}$ as it converges to its steady state value. We simulated the model for different parameter configurations and different initial values of the exchange rate. In each case we found that the variance ratio converged to 1 as the system approached the steady state. In section 3.2 we describe in more detail how these simulations are set up.

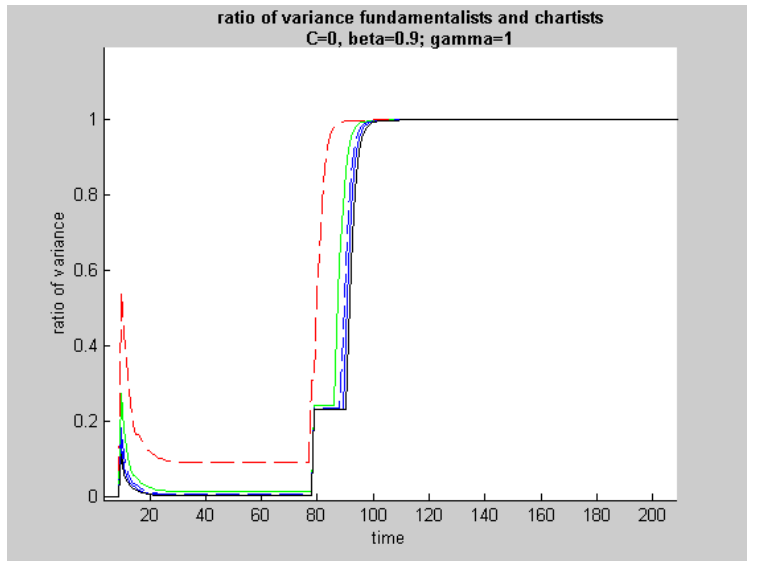

Figure 10: 


\section{B Appendix 2: Numerical values of the para- meters used in the base simulation}

In the following table we present the numerical values of the model. In the first column we listed the parameters of the model, in the second column we present the numerical values in the base simulations. The last column indicates whether or not we have performed a sensitivity analysis on these numerical values. If not, we use the same numerical value in all simulations.

Table 5: Numerical values of parameters

\begin{tabular}{|c|c|c|}
\hline Parameters & values & sensitivity analysis \\
\hline$\psi$ & 0.2 & No \\
$\alpha_{1}, \alpha_{2}, \alpha_{3}, \alpha_{4}, \alpha_{5}$ & $0.44,0.26,0.16,0.09,0.05$ & No \\
$\beta$ & 0.8 & Yes \\
$\theta$ & 0.6 & No \\
$\gamma$ & 1 & Yes \\
$\mu$ & 1 & No \\
$C$ & 5 & Yes \\
$r$ and $r^{*}$ & 0 & No \\
\hline
\end{tabular}




\section{Earlier Working Papers:}

Inflation Forecast Targeting: the Swedish Experience by Claes Berg . 2000:100

Wage Effects of Mobility, Unemployment Benefits and Benefit Financing

by Hans Lindblad. 2000:101

A Bivariate Distribution for Inflation and Output Forecasts

by Mårten Blix and Peter Sellin .... 2000:102

Optimal Horizons for Inflation Targeting

by Nicoletta Batini and Edward Nelson. 2000:103

Empirical Estimation and the Quarterly Projection Model:

An Example Focusing on the External Sector

by Robert Amano, Don Coletti and Stephen Murchison

Conduction Monetary Policy with a Collegial Bord:

The New Swedish Legislation One Year On by Claes Berg and Hans Lindberg

Price-level targeting versus inflation targeting in a forward-looking model

by David Vestin

Unemployment and Inflation Regimes by Anders Vredin and Anders Warne 2000:107

An Expectations-Augmented Phillips Curve in an Open Economy by Kerstin Hallsten 2000:108

An alternative interpretation of the recent U.S. inflation performance

by Mikael Apel and Per Jansson.... 2000:109

Core inflation and monetary policy by Marianne Nessén and UIf Söderström 2000:110

Estimating the Implied Distribution of the Future Short-Term Interest Rate

Using the Longstaff-Schwartz Model by Peter Hördahl. 2000:111

Financial Variables and the Conduct of Monetary Policy

by Charles Goodhart and Boris Hofmann

Testing for the Lucas Critique: A Quantitative Investigation by Jesper Lindé ................................. 2000:113

Monetary Policy Analysis in Backward-Looking Models by Jesper Lindé....................................... 2000:114

UIP for short investments in long-term bonds by Annika Alexius ................................................. 2000:115

Qualitative Survey Responses and Production over the Business Cycle

by Tomas Lindström

Supply stocks and real exchange rates by Annika Alexius ..................................................... 2000:117

Casuality and Regime Inference in a Markov Switching VAR by Anders Warne ........................... 2000:118

Average Inflation Targeting by Marianne Nessén and David Vestin ............................................ 2000:119

Forecast-based monetary policy in Sweden 1992-1998: A view from within

by Per Jansson and Anders Vredin ......................................................................... 2000:120

What have we learned from empirical tests of the monetary transmission effect?

by Stefan Norrbin

Simple monetary policy rules and exchange rate uncertainty

by Kai Leitemo and UIf Söderström

Targeting inflation with a prominent role for money

by Ulf Söderström

Is the Short-run Phillips Curve Nonlinear? Empirical Evidence for Australia, Sweden

and the United States by Ann-Charlotte Eliasson

An Alternative Explanation of the Price Puzzle by Paolo Giordani ............................................. 2001:125

Interoperability and Network Externalities in Electronic Payments by Gabriela Guibourg................ 2001:126

Monetary Policy with Incomplete Exchange Rate Pass-Through by Malin Adolfson ...................... 2001:127

Micro Foundations of Macroeconomic Price Adjustment: Survey Evidence from

Swedish Firms by Mikael Apel, Richard Friberg and Kerstin Hallsten....

Estimating New-Keynesian Phillips Curves on Data with Measurement Errors:

A Full Information Maximum Likelihood Approach by Jesper Lindé

The Empirical Relevance of Simple Forward- and Backward-looking Models:

A View from a Dynamic General Equilibrium Model by Jesper Lindé

Diversification and Delegation in Firms by Vittoria Cerasi and Sonja Daltung 2001:131

Monetary Policy Signaling and Movements in the Swedish Term Structure of Interest Rates

by Malin Andersson, Hans Dillén and Peter Sellin ....

Evaluation of exchange rate forecasts for the krona's nominal effective exchange rate by Henrik Degrér, Jan Hansen and Peter Sellin .... 
Implications of Exchange Rate Objectives under Incomplete Exchange Rate Pass-Through by Malin Adolfson

Incomplete Exchange Pass-Through and Simple Monetary Policy Rules

by Malin Adolfson

Financial Instability and Monetary Policy: The Swedish Evidence

by U. Michael Bergman and Jan Hansen

Finding Good Predictors for Inflation: A Bayesian Model Averaging Approach

by Tor Jacobson and Sune Karlsson

How Important Is Precommitment for Monetary Policy?

by Richard Dennis and UIf Söderström

Can a Calibrated New-Keynesian Model of Monetary Policy Fit the Facts?

by Ulf Söderström, Paul Söderlind and Anders Vredin

Inflation Targeting and the Dynamics of the Transmission Mechanism

by Hans Dillén....

Capital Charges under Basel II: Corporate Credit Risk Modelling and the Macro Economy

by Kenneth Carling, Tor Jacobson, Jesper Lindé and Kasper Roszbach

Capital Adjustment Patterns in Swedish Manufacturing Firms: What Model Do They Suggest?

by Mikael Carlsson and Stefan Laséen

Bank Lending, Geographical Distance, and Credit risk: An Empirical Assessment

of the Church Tower Principle by Kenneth Carling and Sofia Lundberg ....

Inflation, Exchange Rates and PPP in a Multivariate Panel Cointegration Model

by Tor Jacobson, Johan Lyhagen, Rolf Larsson and Marianne Nessén

Evaluating Implied RNDs by some New Confidence Interval Estimation Techniques

by Magnus Andersson and Magnus Lomakka

Taylor Rules and the Predictability of Interest Rates

by Paul Söderlind, Ulf Söderström and Anders Vredin

Inflation, Markups and Monetary Policy

by Magnus Jonsson and Stefan Palmqvist.

Financial Cycles and Bankruptcies in the Nordic Countries by Jan Hansen .....

Bayes Estimators of the Cointegration Space by Mattias Villani.....

Business Survey Data: Do They Help in Forecasting the Macro Economy?

by Jesper Hansson, Per Jansson and Mårten Löf

The Equilibrium Rate of Unemployment and the Real Exchange Rate:

An Unobserved Components System Approach by Hans Lindblad and Peter Sellin..... 2003:152

Monetary Policy Shocks and Business Cycle Fluctuations in a

Small Open Economy: Sweden 1986-2002 by Jesper Lindé

Bank Lending Policy, Credit Scoring and the Survival of Loans by Kasper Roszbach ....................... 2003:154

Internal Ratings Systems, Implied Credit Risk and the Consistency of Banks' Risk

Classification Policies by Tor Jacobson, Jesper Lindé and Kasper Roszbach

Monetary Policy Analysis in a Small Open Economy using Bayesian Cointegrated

Structural VARs by Mattias Villani and Anders Warne....

Indicator Accuracy and Monetary Policy: Is Ignorance Bliss? by Kristoffer P. Nimark ..................... 2003:157

Intersectoral Wage Linkages in Sweden by Kent Friberg ..................................................... 2003:158

Do Higher Wages Cause Inflation? by Magnus Jonsson and Stefan Palmqvist ............................... 2004:159

Why Are Long Rates Sensitive to Monetary Policy by Tore Ellingsen and UIf Söderström .............. 2004:160

The Effects of Permanent Technology Shocks on Labor Productivity

and Hours in the RBC model by Jesper Lindé ...................................................................... 2004:161

Credit Risk versus Capital Requirements under Basel II: Are SME Loans and Retail

Credit Really Different? by Tor Jacobson, Jesper Lindé and Kasper Roszbach 
Sveriges Riksbank

Visiting address: Brunkebergs torg 11

Mail address: se-103 37 Stockholm 